\title{
DNAPLS AT DOE SITES: BACKGROUND AND ASSESSMENT OF CHARACTERIZATION TECHNOLOGIES
}

Gregor A. Junk and William J. Haas Jr.

\author{
Ames Laboratory \\ lowa State University \\ Ames, IA 50011
}

Prepared for the U. S. Department of Energy

Office of Environmental Restoration and Waste Management Office of Technology Development

Characterization, Monitoring, and Sensor Technology Integrated Program

Date Transmitted: December 1993

"Operated by lowa State University for the U. S. Department of Energy under Contract No. W-7405-ENG-82 


\section{ACKNOWLEDGMENTS}

Funding for this work was provided by the Characterization, Monitoring, and Sensor Technologies Integrated Program, Office of Technology Development, Office of Environmental Restoration and Waste Management, U. S. Department of Energy.

Ames Laboratory is operated by lowa State University for the U. S. Department of Energy under Contract No. W-7405-ENG-82.

The efforts of Robert M. Cohen, Thomas O. Early, James W. Mercer, Charles J. Newell, and Stephen G. Schmelling in the timely reviews of this report are gratefully acknowledged. 


\section{CONTENTS}

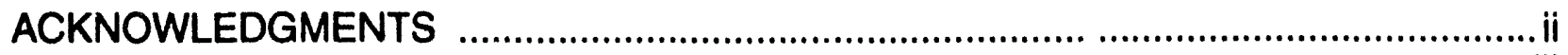

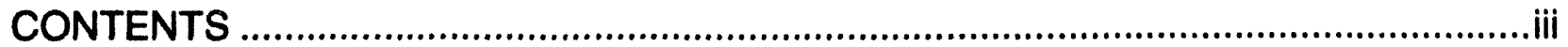

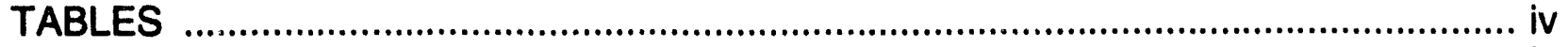

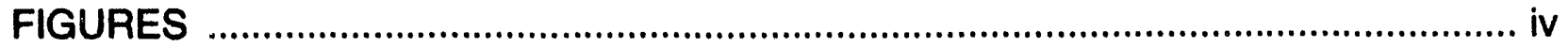

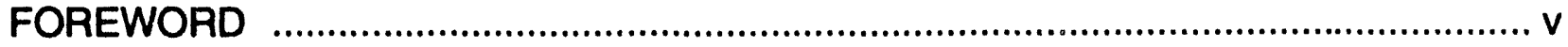

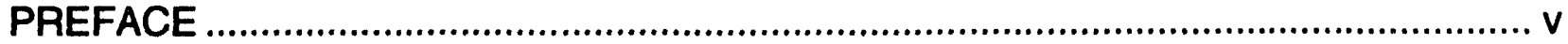

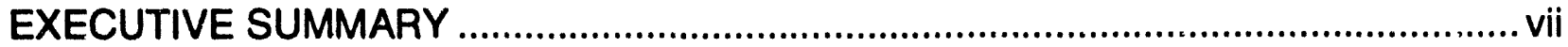

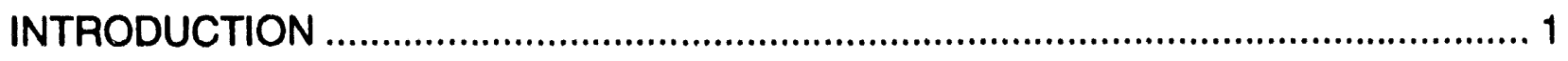

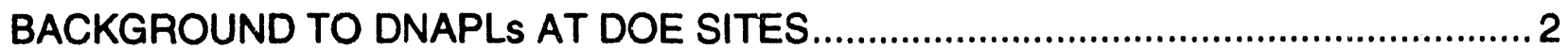

Probable Occurrence of CI VOCs as DNAPLs at DOE Sites ................................. 2

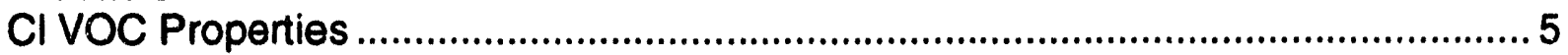

Subsurface Characteristics...................................................................................... 5

Illustrations of $\mathrm{CI}$ VOC iMigration and Contamination of Groundwater ........................6 6

Site Characterization Approach and Conceptual Models ............................................ 9

CHARACTERIZATION TECHNOLOGIES FOR DNAPL SITES ................................ 11

Ideal Site Characterization ................................................................................ 11

Background to Sections on Site Characterization Technologies .............................. 11

Geophysical Technologies ............................................................................... 12

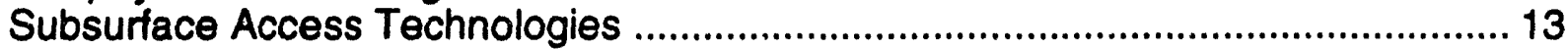

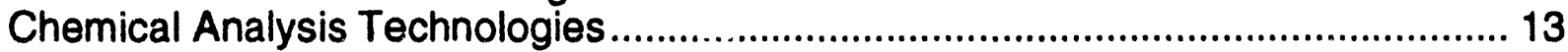

Sample Collection for CI VOCs Analysis ......................................................... 15

Tools for Analysis of Samples for CI VOCs ........................................................... 16

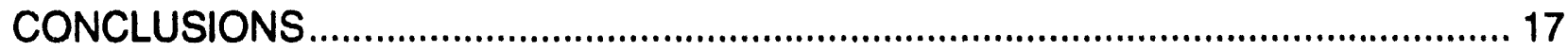

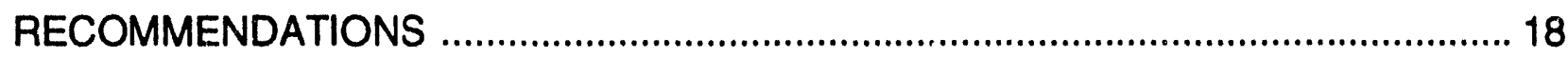

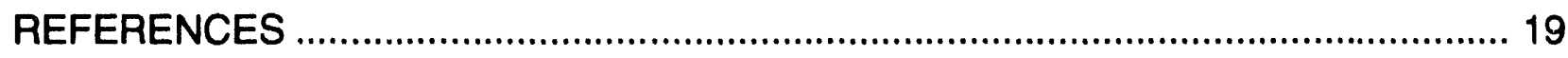

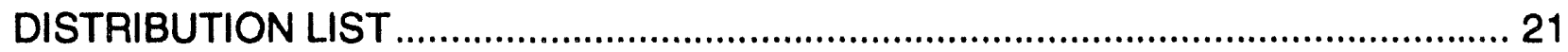

APPENDIX A

Summary Statements About DNAPL Site Characterization and Associated

Technologies

APPENDIX B

Estimating Potential for Occurrence of DNAPL at Superfund Sites

APPENDIX C

Glossary 


\section{TABLES}

Table 1. Features of this report and the EPA DNAPL reports ...................................... 2

Table 2. Examples of some estimated $\mathrm{CI}$ VOC releases at selected DOE sites ............ 4

Table 3. Some techniques for direct detection of CI VOCs as DNAPL ......................... 14

\section{FIGURES}

Figure 1. Decision tree and matrix for estimating potential of DNAPL presence 3

Figure 2. Groundwater contamination caused by release of sufficient TCE liquid to establish DNAPL as residual saturation in the vadose zone 6

Figure 3. Groundwater contamination caused by release of sufficient TCE liquid to establish DNAPL as residual saturation in both the vadose and saturated zones and a DNAPL pool 8

Figure 4. Flow chart for characterization of DNAPL sites 10 


\section{FOREWORD}

The Characterization, Monitoring, and Sensor Technology Integrated Program (CMST-IP) within the Office of Technology Development (OTD) has responsibility for identification, evaluation, and delivery of technologies needed for the work of the Department of Energy's Office of Environmental Restoration and Waste Management. This report addresses part of that responsibility by providing summary information on DNAPL site characterization.

\section{PREFACE}

A dense nonaqueous phase liquid (DNAPL) is a source of contamination that can persist in the subsurface for decades before dissipating completely into the vapor phase and groundwater. The DNAPL chemicals of particular concern to the DOE are chlorinated volatile organic compounds ( $\mathrm{Cl}$ VOCs) such as carbon tetrachloride $(\mathrm{CCl} / 4)$, trichloroethylene (TCE), and perchloroethylene (PCE). These CI VOCs were used in multiple ton quantities at DOE sites and were often released to the subsurface. The predicted fate of released $\mathrm{CI}$ VOC liquid is ciownward movement through the soil under the force of gravity. As it moves, some of the $\mathrm{CI}$ VOC liquid becomes trapped in the soil pores as residual saturation. The liquid also moves rapidly downward if small fractures are present. This migration continues until an impermeable or semi-permeable layer is encountered. Then lateral movement or spreading occurs. The downward and lateral migration in the subsurface leads to DNAPL pools, lenses, and residual saturation that can cause long-term contamination of groundwater at levels well above drinking water standards.

Although $\mathrm{CI}$ VOCs have been detected as dissolved components in the groundwater and as vapor in the soil gas at several DOE sites, direct evidence of their presence as DNAPL is sparse and no measurements of the amounts of DNAPL present within a 
given volume of subsurface have been made. Consequently, unresolved DNAPL issues exist at DOE sites. 


\section{EXECUTIVE SUMMARY}

This report presents:

- a roadmap to literature resources for DOE personnel interested in DNAPLs;

- a brief background for a beginning understanding of the complexity of DNAPL migration and contamination of groundwater;

- a short summary of the EPA-recommended conceptual model approach to DNAPL site characterization;

- an overview of characterization technologies applicable to DNAPLs;

- conclusions and summary statements (see Appendix A) about DNAPL site characterization; and

- general recommendations concerning development of technologies for DNAPL site characterization.

The recommendations, listed below, are based on interpretation of the DNAPL

literature, information presented in the body of this report, and the authors' knowledge of

DOE sites. Implementation of these recommendations is expected to expedite DNAPL site characterization.

1. Technology development decisions should be made recognizing that the EPA approach to DNAPL site characterization, as summarized here and detailed in EPA documents, will probably be followed at DOE sites.

2. Proposals claiming to address DNAPL site characterization should be evaluated by people familiar with sound approaches for that work as well as by experts in the proposed technology area(s).

3. Better ways to estimate the boundaries of a DNAPL zone should be developed.

4. Research aimed at providing methods for estimating the amount present within a DNAPL zone, and the distribution as pools, lenses, and residual saturation should be encouraged.

5. Development of devices that require deployment into the subsurface for DNAPL measurement should not be supported because they have limited value for the characterization of DNAPL sites.

6. Innovative applications of soil gas measurements, such as during changing, continuous, and intermittent sampling, should be explored for usefulness in DNAPL site characterization.

7. Improvement of existing characterization technologies should be sought rather than development of new ones because timely decisions concerning characterization, risk, and remediation of DNAPL sites and return on investment are desired. 
This page is intentionally blank. 


\title{
DNAPLS AT DOE SITES: BACKGROUND AND ASSESSMENT OF CHARACTERIZATION TECHNOLOGIES
}

\author{
Gregor A. Junk and William J. Haas Jr. \\ Ames Laboratory \\ lowa State University \\ Ames, IA 50011
}

\section{INTRODUCTION}

The literature related to DNAPLs has been under study recently by the Characterization, Monitoring, and Sensor Technology Integrated Program for the following reasons:

- the probable existence of DNAPL problems at DOE sites;

- the presence of DNAPLs can dramatically increase the duration and cost of remediation efforts; and

- the need to acquire better background for evaluation of technology developments pertinent to DNAPL site characterization.

Fortunately, in the same period, the U. S. EPA Robert S. Kerr Environmental Research Laboratory was instrumental in the generation of several excellent reports that provide detailed discussions of DNAPL issues (Cohen and Mercer 1993; Harwell and Krebs-Yuill 1992; Henrysson and McCarty 1992; Huling and Weaver 1991; Kimball and Bates 1992; Mercer and Spalding 1991; Miller 1992; Newell et al. 1992; Newell and Ross 1992; Olhoeft 1992; U. S. EPA 1992; Wilson et al. 1990). We have drawn heavily iiom these works in our attempt to produce a report focused on suspected DNAPL problems at DOE sites, currently available technologies for DNAPL site characterization, and recommendations concerning development of those technologies. Features of this report and the EPA DNAPL reports are compared in Table 1. 
Table 1. Features of this report and the EPA DNAPL reports.

\begin{tabular}{|l|l|}
\hline This report & EPA reports \\
\hline $\begin{array}{l}\text { Presents two simplistic scenarios of DNAPL } \\
\text { migration and contamination. }\end{array}$ & Present many detailed scenarios. \\
\hline $\begin{array}{l}\text { Provides a limited discussion of DNAPL properties } \\
\text { and subsurface characteristics. }\end{array}$ & Provide a broad range of detailed discussions. \\
\hline Focuses on DNAPL problems at DOE sites. & Address all DNAPL sites. \\
\hline Addresses DNAPL problems only. & $\begin{array}{l}\text { Give some attention to LNAPL as well as DNAPL } \\
\text { problems. }\end{array}$ \\
\hline Addresses only CI VOCs as DNAPLs. & Consider all chemicals that can exist as DNAPLs. \\
\hline Principal focus is on characterization. & $\begin{array}{l}\text { Address remediation and characterization, with } \\
\text { emphasis on remediation. }\end{array}$ \\
\hline
\end{tabular}

\section{BACKGROUND TO DNAPLS AT DOE SITES}

Some basic information concerning DNAPLs is presented here as background for the following sections on characterization technologies, conclusions, and recommendations. Additional summary statements pertinent to DNAPL site characterization and associated technologies are given in Appendix $A$.

\section{Probable Occurrence of $\mathrm{CI}$ VOCs as DNAPLs at DOE Sites}

The EPA has published a valuable report on categorizing the probability of a DNAPL occurrence at a site (Newell and Ross 1992). This report is attached as Appendix B. In Figure 1, somewhat different language has been used and three of the EPA charts have been combined along the lines employed by Cohen and Mercer (1993) to produce a decision tree and a DNAPL potential matrix for CI VOCs at DOE sites. 


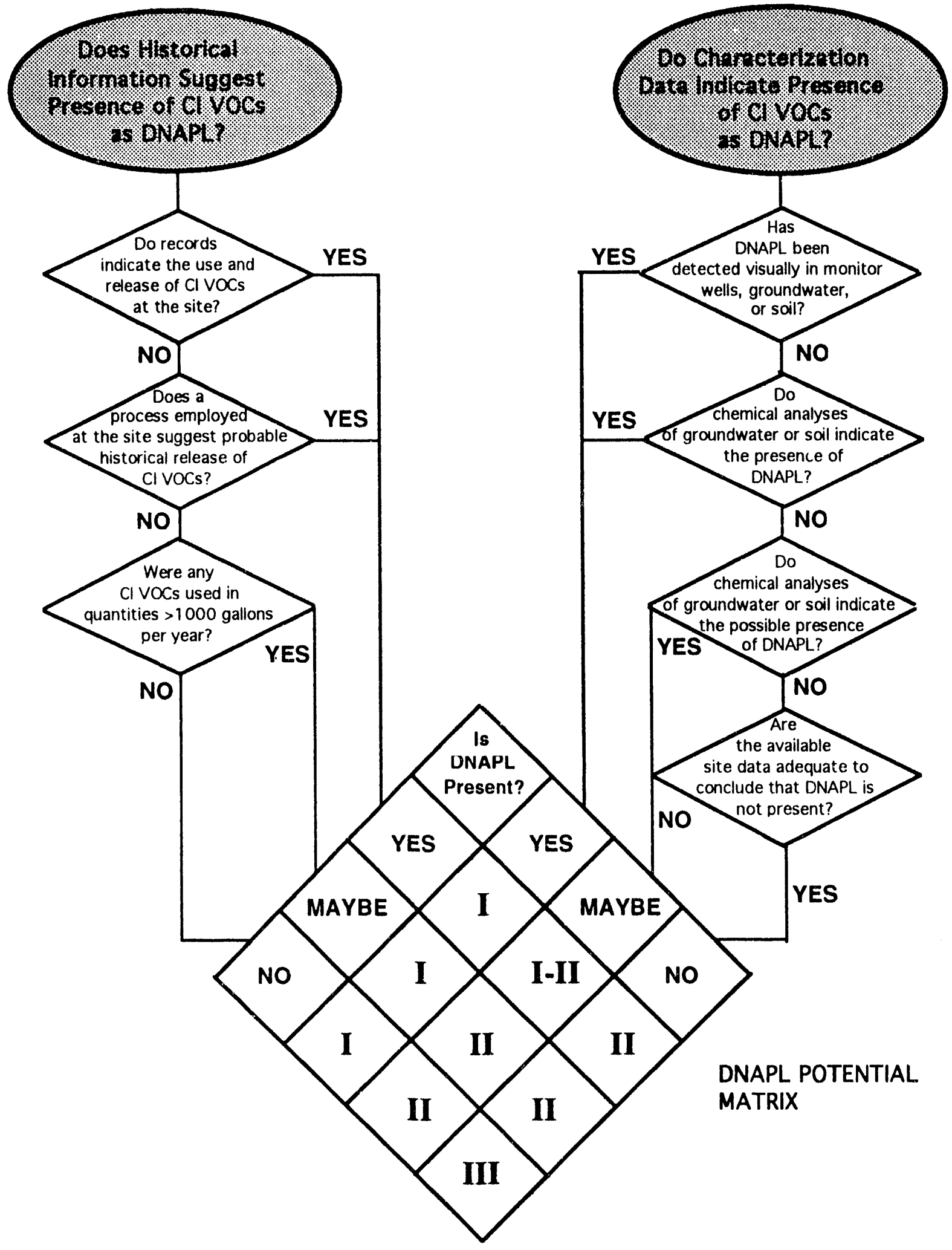

Figure 1. Decision tree and matrix for estimating potential of DNAPL preserice: I=confirmed or high potential; II=moderate potential; III=low potential [modified from Newell and Ross (1992) and Cohen and Mercer (1993)]. 
When the history of DOE production processes and estimated release data such as the very few examples given in Table 2 are considered, the potential for presence of DNAPL at DOE sites is moderate to high. For a contamination perspective, one kilogram of $\mathrm{Cl} \mathrm{VOC} \mathrm{in} \mathrm{the} \mathrm{subsurface} \mathrm{can} \mathrm{eventually} \mathrm{contaminate} 200$ million liters of groundwater at the drinking water standard of 5 parts per billion.

Table 2. Examples of some estimated CI VOC releases at selected DOE sites.

\begin{tabular}{|l|c|c|c|}
\hline \multicolumn{1}{|c|}{ SITE } & \multicolumn{3}{c|}{ Kg Released } \\
\cline { 2 - 4 } & TCE & PCE & CCl4 \\
\hline Savannah River, Settling Basina & 140,000 & 820,000 & $b$ \\
\hline Westinghouse Hanford Corporationc & $b$ & $b$ & 750,000 \\
\hline $\begin{array}{l}\text { Radioactive Waste Management Center, } \\
\text { INELd }\end{array}$ & $35,000 \Theta$ & $39,000 \Theta$ & 140,000 \\
\hline $\begin{array}{l}\text { Paducah Gaseous Diffusion Plant, } \\
\text { C400 Degreasing Facility }\end{array}$ & $2,000,000$ & $b$ & $b$ \\
\hline Chemical Waste Landfill, Sandiag & 32,000 & $b$ & $b$ \\
\hline
\end{tabular}

a from Looney, Rossabi, et al. (1992, p. 15)

$b$ no estimated amount given

c from Last and Rohay (1993, p. 5.1)

d from Walton et al. (1992, p. 92)

$e$ assuming the release of equal volumes of TCE, PCE, TCA, and $\mathrm{CHCl}_{3}$

$f$ from J. L. Clausen, Oak Ridge National Laboratory (personal communication, November 1993). It is assumed that the majority was lost to the atmosphere by volatilization, with an unknown quantity released to the subsurface through a sump.

$g$ from Conrad et al. (1992, p. 137)

The migration of these CI VOCs as DNAPLs that eventually contaminate the groundwater depends on the properties of the CI VOCs and the subsurface characteristics. Some of these properties and characteristics are discussed here as an introduction to two simplistic illustrations of how groundwater becomes contaminated. 
The illustrations and discussion are intended to provide only a cursory understanding of DNAPL behavior in the subsurface. For more detailed treatment, the reader is referred to the documents listed in the reference section.

\section{VOC Properties}

Properties that influence the migration of $\mathrm{Cl}$ VOCs in the subsurface are density, viscosity, solubility, vapor pressure, volatility, interfacial tension, and wettability. These properties are discussed in detail by Cohen and Mercer (1993). For a cursory understanding of groundwater contamination by $\mathrm{Cl}$ VOCs, the most important properties are density, viscosity, and solubility.

The CI VOC liquid is more dense than water so it will sink as a separate phase; the $\mathrm{CI}$ VOC vapor is more dense than air so it will tend to move downward in the vadose zone. The liquid is less viscous than water so it will infiltrate the subsurface more rapidly and even penetrate layers impermeable to water. The solubility of a CI VOC is sufficient to contaminate water above the drinking water standard, but so low that a separate phase exists in the presence of water.

\section{Subsurface Characteristics}

The most important subsurface characteristic is heterogeneity. Differences in the subsurface, between and within sites, complicate DNAPL migration and the eventual contamination of groundwater. Consequently, the EPA documents (Cohen and Mercer 1993; Huling and Weaver 1991; U. S. EPA 1992; Newell and Ross 1992) provide many excellent illustrations and discussions of DNAPL migration and contamination and effectively stress that the characterization and remediation actions are site specific. Only two simplistic contamination scenarios are illustrated here to provide background for a beginning understanding of DNAPL migration and contamination of groundwater. 


\section{Illustrations of $\mathrm{Cl}$ VOC Migration and Contamination of Groundwater}

In the illustrations given here, TCE is used as an example of $\mathrm{Cl}$ VOC present as DNAPL. The definitions of the terms used in the discussions of these illustrations of DNAPL migration and contamination are given in the Appendix $\mathrm{C}$ glossary.

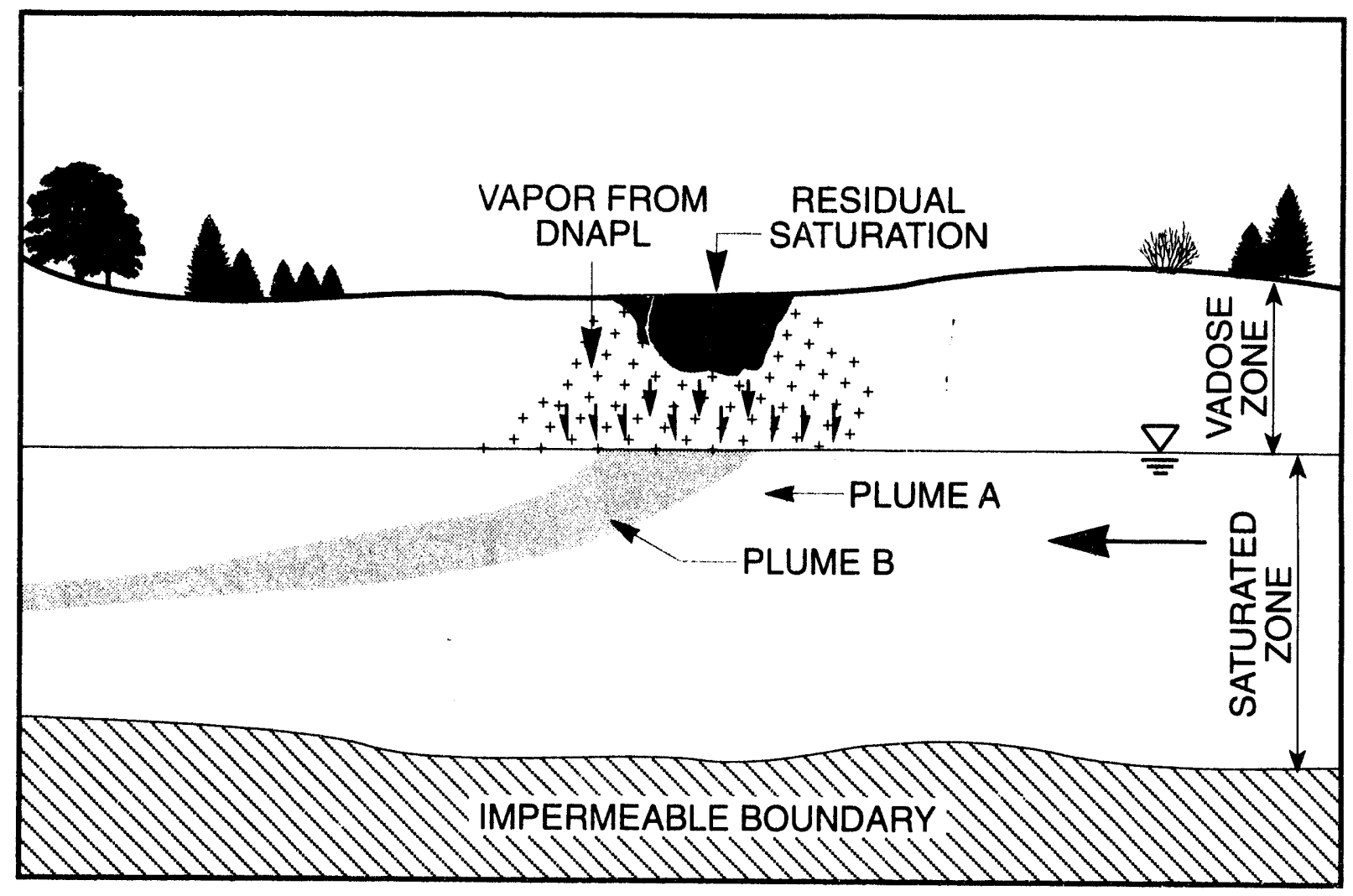

Figure 2. Groundwater contamination caused by release of sufficient TCE liquid to establish DNAPL as residual saturation in the vadose zone [modified from Newell and Ross (1992)].

Plume A - contamination from density-driven migration of vapors from the vadose zone to the water table plus contamination caused by infiltration through the vapor zone.

Plume B - contamination caused mainly by infiltration and leaching of the residual saturation.

The first illustration (Figure 2) addresses the release of sufficient TCE liquid, a potential DNAPL typical of CI VOCs at DOE sites, to establish residual saturation in the vadose zone. Here the TCE migrates downward, primarily under the force of gravity. When there is no excess of liquid TCE at the surface, the subsurface liquid no longer 
holds together as a continuous phase and small isolated pockets of liquid TCE are retained in the porous media as residual saturation. The groundwater becomes contaminated by the following mechanisms: (1) density-driven migration of the vapor to the water table, where a portion of it dissolves to form a shallow plume of contamination; (2) infiltration through the vadose zone, where TCE vapor is dissolved and carried to the water table (indicated by half arrows in Figure 2); and (3) infiltration and leaching through the residual saturation (indicated by full arrows).

When considering contamination from DNAPL, it is important to realize that the residual saturation is essentially an immobile source of groundwater contamination and that the volumetric retention capacity of the soil is very large. For example, a vadose zone soil column at residial saturation can immobilize an amount of TCE equal to about $10 \%$ of the pore volume. In the saturated zone, the subsurface column can retain as high as $50 \%$ of the pore volume as trapped TCE. 


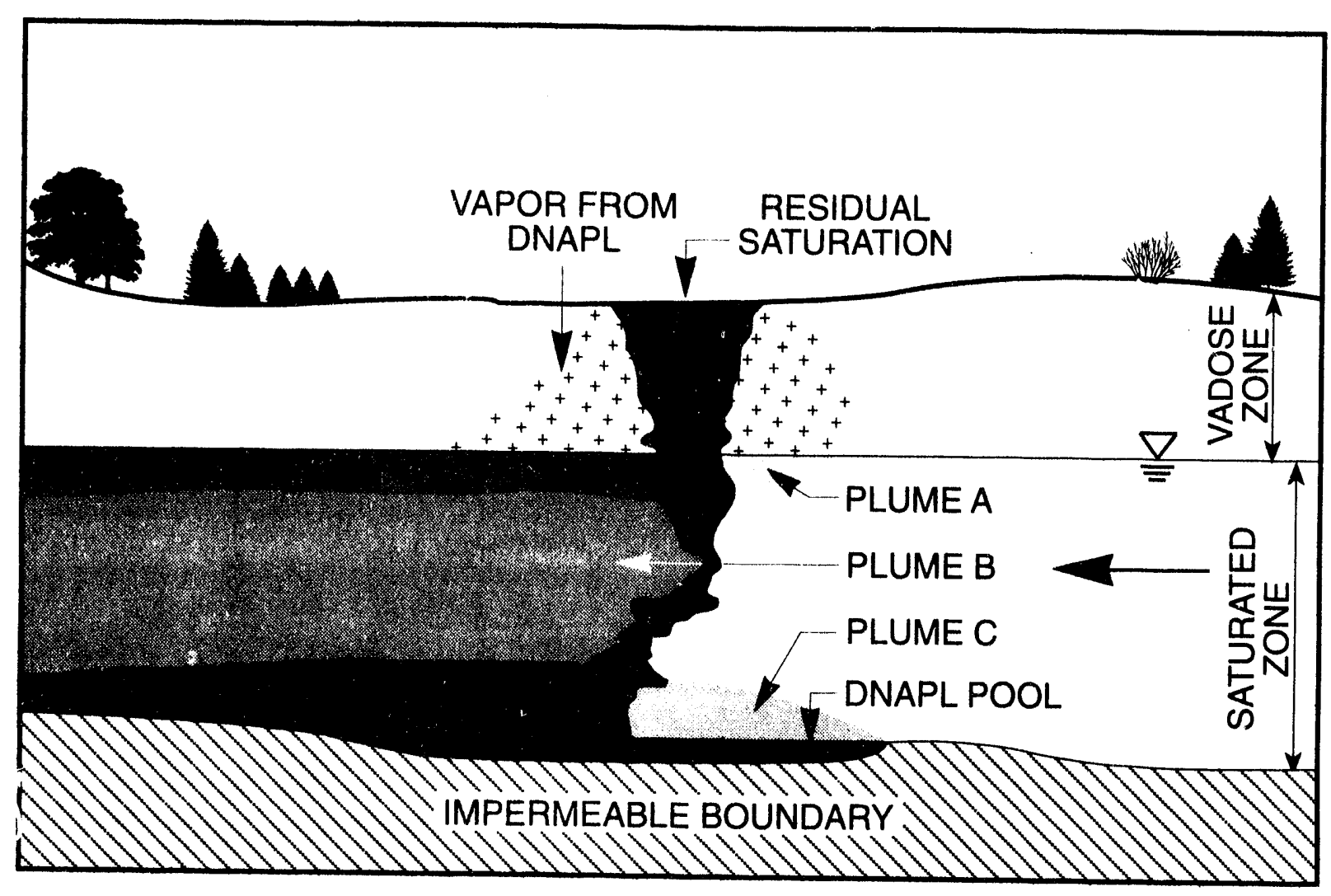

Figure 3. Groundwater contamination caused by release of sufficient TCE liquid to establish DNAPL as residual saturation in both the vadose and saturated zones and a DNAPL pool.

Plume A - shallow contamination from density-driven migration of vapors from the vadose zone to the water table.

Plume B - contamination caused by dissolution from residual saturation in the saturated zone.

Plume C - deep contamination caused by continuous dissolution from the DNAPL pool.

The second illustration (Figure 3) addresses the release of sufficient TCE to establish residual saturation in both the vadose and saturated zones and to form a DNAPL pool at the impermeable boundary. In this case, the groundwater becomes contaminated primarily by dissolution of the TCE from the residual saturation in the saturated zone and from dissolution from the DNAPL pool. As can be seen in Figure 3 , the DNAPL pool also causes unexpected upstream extension of the plume. The actual 
situation is more complicated because of the additional contamination, not shown in Figure 3, caused by infiltration and leaching from the vadose zone. Consequently, the DNAPL, under the conditions shown in Figure 3 , creates a considerably more complex pattern of contamination than that shown in Figure 2. This complexity is present even when the subsurface, as shown in both figures, is homogeneous.

In the real world, of course, the subsurface is heterogeneous. As a result, the migrations and contaminations are even more complex. For example, complicated migrations of DNAPL through subsurface fractures certainly occur at many DOE sites contaminated by $\mathrm{Cl}$ VOCs. These migrations, as well as confounding factors such as DNAPL mixtures, phase interactions, degradations, and especially the heterogeneity and even microheterogeneity of the subsurface, create an extremely complex DNAPL situation. This complexity necessitates careful and intelligent use of the conceptual model approach for site characterization.

\section{Site Characterization Approach and Conceptual Models}

When DNAPLs are suspected, an iterative approach based on the development and refinement of a conceptual model is used. This approach to site characterization is shown in the Figure 4 flow chart. The process begins with review of all existing data as potential inputs for the development of the initial conceptual model by personnel having an understanding of the DNAPL issue (i. e., DNAPL properties and migration, subsurface characteristics, and the contamination mechanisms). The first field work involves invasive and noninvasive activities outside the suspected DNAPL zone and only noninvasive actions inside the zone. Then, if invasive actions inside the DNAPL zone must be undertaken to obtain information essential for characterization, risk, or remediation decisions, that work should be conducted with extreme caution to avoid mobilization of the DNAPL. 


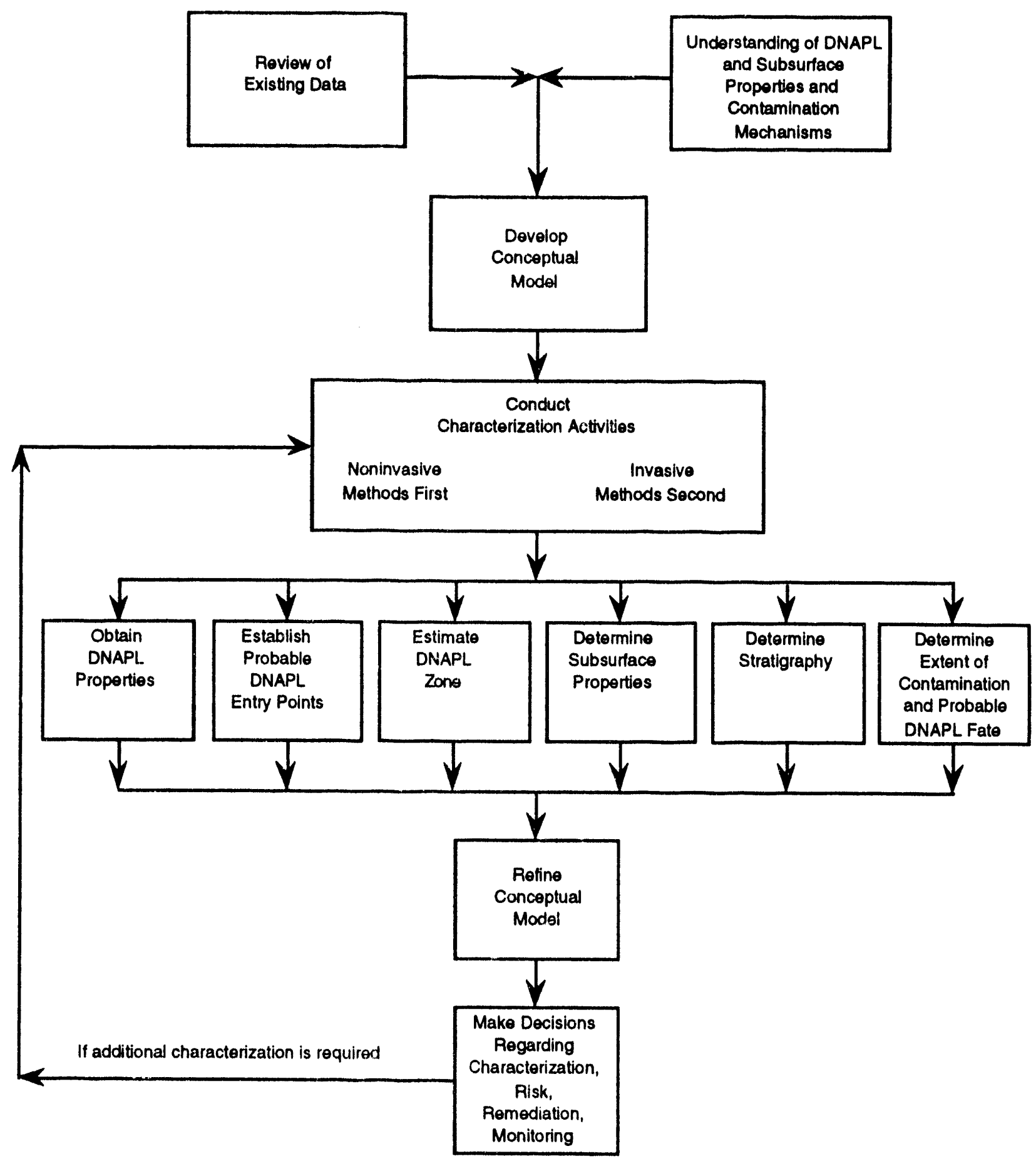

Figure 4. Flow chart for characterization of DNAPL sites [modified from Cohen and Mercer (1993)]. 


\section{CHARACTERIZ.ATION TECHNOL.OGIES FOR DNAPL SITES}

\section{Ideal Site Characterization}

Ideal site characterization would include a complete description of the normally complex subsurface, detailed knowledge of the behavior of a DNAPL or mixture in that subsurface, and information concerning the DNAPL boundaries, the amount present within those boundaries, and the distribution as free-phase pools, lenses, and residual saturations. This cannnt be done using existing technologies.

Previous sections of this report suggest that the behavior of DNAPLs in the com/ lex heterogeneous subsurface is one reason site characterization is likely to be less than ideal. Another reason is deficiencies in the available characterization technologies. Tool improvements and the development of new tools such that the ideal site characterization can be accomplished is not expected.

In the absence of ideal characterization, intelligence must be applied to the interpretation of archived and newly obtained data such that good, albeit still questionable, decisions regarding characterization, risk, and remediation can be made. Naturally, this interpretation should be performed by personnel who have detailed knowledge of the sampling procedures and the geophysical, subsurface access, and chemical analysis technologies.

\section{Background to Sections on Site Characterization Technologies}

Geophysical, subsurface access, and chemical analysis technologies used for site characterization are discussed separately below. The chemical analysis technologies generally provide more definitive information than the geophysical methods. For example, some chemical methods can directly detect the presence of DNAPL. In contrast, none of the geophysical methods have clearly demonstrated potential for detecting the presence of DNAPL or for addressing the two major problems of defining the boundaries of the DNAPL zone and of determining the amounts of the different 
forms of DNAPL that may be present. Chemical analysis technologies have reasonable potential for addressing both these problems.

Two subsections of chemical analysis titled "Sample Collection for $\mathrm{Cl}$ VOCs Analyses" and "Tools for Analyses of CI VOCs" are included. These subsections are presented because data from measurements of $\mathrm{Cl}$ VOCs in gas, water, soil, and sediment samples are essential inputs to developing and refining the conceptual model.

\section{Geophysical Technologies}

The noninvasive geophysical technologies, ground-penetrating radar, electromagnetic conductivity, electrical resistivity, and seismic refraction and reflection, are discussed by Cohen and Mercer (1993). These and some invasive methods are useful for the delineation of subsurface geology and stratigraphy. This information is essential for making defensible risk and remediation decisions. It also has clear value for predicting where DNAPLs are likely, or unlikely, to be found.

In dynamic situations, geophysical methods such as ground-penetrating radar have some potential for monitoring DNAPL movement. This was shown in connection with the controlled release of PCE at the Borden site in Canada (Greenhouse et al. 1993). Further tests and development of these methods for application to monitoring remediation processes are probably justified.

In static situations, no current geophysical methods have clear capability for detecting the presence of DNAPL or for the determination of the boundaries and amounts of the different DNAPL forms. In the near term, the potential appears to be low for development of geophysical methods to detect static DNAPLs and define boundaries. In both the near and long term, the potential seems very low for jecphysical determination of amounts of the different DNAPL forms. 


\section{Subsurface Access Technologies}

Subsurface access technologies employ a wide variety of drilling, coring, and push equipment. Descriptions and discussions of their use and limitations are given in Cchen and Mercer (1993). These technologies are used to acquire iniormation about the site based on observations recorded during the penetration of the subsurface and to collect samples for chemical and other analyses. These analyses produce data that aid in characterization of the site.

In general, current subsurface access tools are adequate for drilling boreholes and installing wells. Satisfactory tools are also available for deployment of chemical sensors and for collecting gas, liquid, and solid samples. Development of new or modified access technologies should only be supported if a significant cost advantage can be projected and useful characterization data are likely to be produced.

\section{Chemical Analysis Technologies}

Noninvasive chemical analysis technologies for DNAPLs involve some form of soil gas measurement. These soil gas surveys are usually considered noninvasive even though most involve some minimal invasiveness, either to emplace a sorbent for passive sampling, or to drive a small hollow probe for active sampling. Data from a properly conducted soil gas survey can be used to infer the presence of a DNAPL zone above the water table and to estimate its areal boundary. In some cases where shallow DNAPL is present, the depth boundaries may also be estimated.

All the other chemical analysis technologies used to measure directly DNAPLs, or to infer or suspect the presence of DNAPLs, involve some form of current or past invasive activity. These invasions of the subsurface for direct DNAPL measurements are required to collect samples for analysis or in emplace sensors for detecting the DNAPL. Some techriques for direct detection of CI VOCs as DNAPL are outlined in Table 3. 
Table 3. Some techniques for direct detection of CI VOCs as DNAPL.

\begin{tabular}{|l|l|l|}
\hline Technique & Application & Measurement Principle \\
\hline Interface probe & liquid in well & electrical resistance \\
\hline Transparent bailer & liquid from well & visual \\
\hline Weighted string & liquid in well & smell, visual \\
\hline Hydrocarbon paste & liquid ir well & chemical reaction \\
\hline Hydrophobic dye & collected soil, sediment & add water -- visual \\
\hline Hydrophobic dye & liquid from well & visual \\
\hline Centrifuge & collected soil, sediment & add water -- phase separation \\
\hline Extraction* & collected soil, sediment & GC, GC/MS, IR, etc. \\
\hline
\end{tabular}

* Not exactly direct detection but gives evidence of DNAPL presence and quantitative results.

Cohen and Mercer (1993) provide detailed discussion of these techniques. They have high value for site characterization when collected samples are already available or sample collection or access is convenient, i. e., when wells are already available or being drilled. However, adequate site characterization using such direct detection techniques may require examination of a very large number of samples taken from various depths over a considerable area. Although it may be possible to develop less expensive detection techniques, the cost of accessing the subsurface will likely remain high and the largest part of the total analytical cost.

Frequently, the presence of DNAPL in the subsurface is not measured directly but is inferred or suspected. The inference is based on measurement of CI VOCs in: (1) groundwater at concentrations $>1 \%$ of the aqueous solubility; (2) soil or sediment at concentrations $>1 \%$ by weight; or (3) soil gas at concentrations $>100$ parts per million.

Suspicion of DNAPL presence can be based on the following anomalous $\mathrm{CI}$ VOC results: (1) concentrations increase inexplicably with depth; (2) CI VOCs found 
upgradient from the suspected release area; (3) erratic patterns in groundwater concentrations; (4) erratic and localized high concentration in soil gas; (5) water concentrations that decrease during pump-and-treat but then rebound when pumping is stopped.

All the concentration data used to infer or suspect the presence of DNAPL are accumulated by chemical analysis of gas, water, soil, or sediment samples. The procedures for the analysis of CI VOCs in these kinds of samples are well established.

\section{Sample Collection for $\mathrm{Cl}$ VOCs Analysis}

Various collection procedures are available for gas, water, soil, and sediment samples. In general, no technology development is needed here. The major problem is obtaining samples representative of the region of interest. This is particularly true for DNAPLs since they are not uniformly distributed in the subsurface and small isolated pockets of DNAPL, capable of contaminating large quantities of water, can exist within a few feet of a chosen sample volume.

A problem may occur when historical data from core and water samples are used to inter the presence or absence of $\mathrm{Cl}$ VOCs in the subsurface. Frequently, these samples were handled in a manner that led to loss of some or all of the $\mathrm{Cl}$ VOCs prior to analysis. Conclusive results confirming these losses for core samples were reported at the National Symposium on Measuring and Interpreting VOCs in Soils: State of the Art and Research Needs, Las Vegas, January 12-14, 1993. Robert Siegrist, Oak Ridge National Laboratory, has indicated that summaries and conclusions from this meeting will be available early in 1994 (pers. comm. November 1993). Losses of CI VOCs caused by improper collection and preservation of sediment samples taken from the saturated zone have undoubtedly led to erroneous conclusions of the absence of DNAPL when the Feenstra et al. (1991) procedure was employed. Similar losses 
leading to erroneous conclusions of DNAPL absence can also occur for samples taken from the vadose zone.

\section{Tools for Analyses of Cl VOCs}

Adequate and reliable tools for the analyses of CI VOCs in gas, water, soil, and sediment samples have been available for many years. This is especially true for gas samples. Although OTD support for the development of new instruments has paid dividends in the past, continued funding of such work is not expected to yield a significant return on investment. Nevertheless, some ongoing support for modification of existing instruments to make them more user friendly and field deployable is defensible. Development of simple, rapid, and inexpensive screening procedures for $\mathrm{Cl}$ VOCs should also be supported. The ideal screening procedure would be simple, have sufficient sensitivity, and be free of both false positives and negatives.

Investment in additional techniques for direct detection of DNAPL in the subsurface is not likely to provide a return. This conclusion is reached from consideration of the heterogeneity of the subsurface, the nature of the DNAPL, and the almost certain existence of residual saturation zones where the pockets of DNAPL are very small. Even if inexpensive miniature probes could be developed and emplaced, the number required for adequate definition of a DNAPL zone could be enormous. In some instances, such devices may be useful for detecting pools by probing boreholes but procedures already exist for these measurements and the probability of adequately determining pool volumes with these probes is small. 


\section{CONCLUSIONS}

The more important conclusions of this work are consolidated below. Some additional conclusions are contained in the summary statements of Appendix A.

1. The EPA approach to DNAPL site characterization will probably be employed with only minor modifications at DOE sites because it is fundamentally sound and consistent with regulatory requirements.

2. The probable deep coitamination by CI VOCs as DNAPLs at some DOE sites further complicates th $\Theta$ characterization efforts.

3. No technologies are currently available for measurement of the amount of DNAPL present in pools, lenses, and residual saturation.

4. Soil gas surveys appear to have unexploited potential for noninvasive, or at least minimally invasive, characterization of CI VOCs as DNAPL at DOE sites.

5. Current technologies for measuring $\mathrm{Cl}$ VOCs in the vapor phase, dissolved in water, and as part of a soil or sediment sample are satisfactory; however, the development of simple field screening methods might significantly reduce characterization costs.

6. Appreciable support for development of geophysical methods for locating and estimating the amounts and forms of DNAPLs is probably not warranted.

7. A memorandum similar to U. S. EPA Directive (1992), but specific to Cl VOCs as DNAPLS, would provide useful policy guidance for decisions regarding characterization, risk, and remediation at DOE facilities. 


\section{RECOMMENDATIONS}

The recommendations, listed below, are based on interpretation of the DNAPL literature, information presented in the body of this report, and the authors' knowledge of

DOE sites. Implementation of these recommendations is expected to expedite DNAPL site characterization.

1. Technology developm snt decisions should be made recognizing that the EPA approach to DNAPL site characterization, as summarized here and detailed in EPA documents, will probably be followed at DOE sites.

2. Proposals claiming to address DNAPL site characterization should be evaluated by people famillar with sound approaches for that work as well as by experts in the proposed technology area(s).

3. Better ways to estimate the boundaries of a DNAPL zone should be developed.

4. Research aimed at proviciing methods for estimating the amount present within a DNAPL zone, and the distribution as pools, lenses, and residual saturation should be encouraged.

5. Development of devices that require deployment into the subsurface for DNAPL measurement should not be supported because they have limited value for the characterization of DNAPL sites.

6. Innovative applications of soil gas measurements, such as during changing, continuous, and intermittent sampling, should be explored for usefulness in DNAPL site characterization.

7. Improvement of existing characterization technologies should be sought rather than development of new ones becalise timely decisions concerning characterization, risk, and remediation of DNAPL sites and return on investment are desired. 


\section{REFERENCES}

Cohen, R. M., and J. W. Mercer. 1993. DNAPL Site Evaluation. CRC Press, Inc.: Boca Raton, FL.

Conrad, S. H., A. M. Parsons, and E. D. Mattson. 1992. The Sniffing Dog Approach to Defining Plumes Emanating from DNAPLs in the Subsurface. Subsurface Restoration Conference Proceedings. National Center for Ground Water Research, Rice University, Houston, TX, pp 136-138.

Greenhouse, J., M. Brewster, G. Schneider, D. Redman, P. Annan, G. Olhoeft, J. Lucius, K. Sander, and A. Mazzella. 1993. Geophysics and Solvents: The Borden Experiment, The Leading Edge, April, pp 261-267.

Harwell, J. H., and B. hrebs-Yuill. 1992. Evaluation of Surfactant Recovery Processes for DNAPL Remediation. Subsurface Restoration Conference Proceedings. National Center for Ground Water Research, Rice University, Houston, TX, pp 230231.

Henrysson, T., and P. L. McCarty. 1992. The Role of Poly-B-hydroxybutyrate in Trichloroethylene Transformation in Methanotrophs. Subsurface Restoration Conference Proceedings. National Center for Ground Water Research, Rice University, Houston, TX, pp 294-296.

Huling, S. G., and J. W. Weaver. 1991. Dense Nonaqueous Phase Liquids. Ground Water Issue, EPA/540/4-91-002.

Kimball, S. L., and M. H. Bates. 1992. The Use of Surfactant-Enhanced Soil Flushing for In Situ Remediation of Hydrophobic Hazardous Wastes in Soil-An Overview. Subsurface Restoration Conference Proceedings. National Center for Ground Water Research, Rice University, Houston, TX, pp 29-31.

Last, G. V., and V. J. Rohay. 1993. Refined Conceptual Model for the Volatile Organic Compounds-Arid Integrated Demonstration and 200 West Area Carbon Tetrachloride Expedited Response Action. PNL-8597.

Looney, B. B., D. S. Kaback, and J. C. Corey. 1992. Environmental Restoration Using Horizontal Wells: A Field Demonstration. Subsurface Restoration Conference Proceedings. National Center for Ground Water Research, Rice University, Houston, TX, pp 41-43.

Looney, B. B., J. Rossabi, D. M. Tuck, J. E. Jordan, C. L. Bergren, R. Van Pelt, W. E. Jones, A. E. Stevenson, and B. S. Kristiansen. 1992. Assessing DNAPL Contamination, A/M-Area, Savannah River Site: Phase 1 Results (U), WSRC-RP. 92-1302.

Mercer, J. W. and C. P. Spalding. 1991. Chapter 5: Characterization of the Vadose Zone. Serninar Publication: Site Characterization for Subsurface Remediation, EPA625/4-01/026, pp 59-71. 
Miller, D. W. 1992. Site Characterization Goals. Subsurface Restoration Conference Proceedings. National Center for Ground Water Research, Rice University, Houston, TX, p 28.

Newell, C. J., J. A. Connor, and T. E. McHugh. 1992. Conceptual Design for Managing Dense Non-Aqueous Phase Liquids (DNAPL) at a Superfund Site. Subsurface Restoration Conference Proceedings. National Center for Ground Water Research, Rice University, Houston, TX, pp 198-200.

Newell, C. J., and R. R. Ross 1992. Estimating Potential for Occurrence of DNAPL at Superfund Sites. EPA Publication: 9355.4-07FS.

Olhoeft, G. R. 1992. Site Characterization Tools. Subsurface Restoration Conference Proceedings. National Center for Ground Water Research, Rice University, Houston, TX, pp 29-31.

U. S. EPA. 1992. Considerations in Ground-Water Remediation at Superfund Sites and RCRA Facilities -- Update. Directive 9283.1-06, Office of Solid Waste and Emergency Response.

U. S. EPA. 1992. Dense Nonaqueous Phase Liquids--A Workshop Summary, EPA600/R-92/030.

Walton, J. C., R. G. Baca, J. B. Sisson, A. J. Sondrup, and S. O. Magnuson. 1992. Applying Computer Simulation Models to Design Large-Scale Soil Venting and Bioremediation System. In Proceedings of the Symposium on Soil Venting, pp 91101. EPA600/R-92/174.

Wilson, J. L., S. H. Conrad, W. R. Mason, W. Peplinski, and E. Hagen. 1990. Laboratory Investigation of Residual Liquid Organics from Spills, Leaks, and the Disposal of Hazardous Wastes in Groundwater, EPA600/6-90/004. 
Ames Laboratory

Office of Information

lowa State University

201 Spedding Hall

Ames, IA 50011-3020

U. S. Department of Energy

Chicago Operations Office

Patent Counsel

9800 South Cass Avenue

Argonne, IL 60439

Director

ISURF

214 Office and Laboratory

lowa State University

Ames, IA 50011-3020

Office of Scientific and

Technical Information

U. S. Department of Energy

P. O. Box 62

Oak Ridge, TN 37830

Caroline Purdy EM-541

Program Manager, CMST-IP

U. S. Department of Energy

Trevion II

12800 Middlebrook Road

Germantown, MD 20874

William J. Haas Jr.

Ames Laboratory

110 Spedding Hall

lowa State University

Ames, IA 50011

Gregor A. Junk

Ames Laboratory

106 Spedding Hall

lowa State University

Ames, IA 50011

Paul W. Wang

Ames Laboratory 106 Spedding Hall lowa State University

Ames, IA 50011

(6)

(1)

)

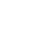


James W. Mercer

GeoTrans, Inc.

46050 Manekin Plaza, Suite 100

Sterling, VA 20166

(1)

Robert M. Cohen

GeoTrans, Inc.

46050 Manekin Plaza, Suite 100

Sterling, VA 20166

Stephen G. Schmelling

Robert S. Kerr Environmental

Research Lab.

US EPA

Ada, OK 74820

Charles J. Newell

Groundwater Services, Inc.

5252 Westchester, Suite 270

Houston, TX 77005

(1)

Thomas O. Early

Oak Ridge National Laboratory

P. O. Box 2008

Oak Ridge, TN 37831-6317

(1)

Members of DNAPL

National Task Team

(20)

Members of Characterization and

Monitoring Technical Support

Group - VOC Arid ID 


\section{APPENDIX A}

\section{Summary Statements About DNAPL Characterization and Associated Technologies}

The statements marked with an asterisk below were adapted from Cohen and Mercer (1993); those marked with a dagger were contributed by Thomas O. Early, Oak Ridge National Laboratory.

1. Chlorinated VOCs have been used in production processes at many DOE sites and have been released to the subsurface in quantities that strongly suggest a DNAPL problem.

2. In only a few cases has direct positive evidence been obtained for $\mathrm{Cl}$ VOC presence as DNAPL.

3. The solutions to DNAPL problems are site specific and all rely on the development of an initial conceptual model and its refinement as new information becomes available.

4. For $\mathrm{Cl}$ VOCs, an understanding of the DNAPL contamination of groundwater can be obtained from straightforward consideration of their density, viscosity, and solubility.

5. The EPA approach to "Estimating Potential for Occurrence of DNAPL at Superfund Sites" (See Appendix B) is applicable to DOE sites.

6. Although some technologies are available for the direct detection of pools of DNAPL, and others could easily be developed, none are expected to become available for the direct determination of the amounts of DNAPL present in various forms, particularly residual saturation, in a defined subsurface volume.

$7^{\star}$. Noninvasive geophysical technologies are applicable for obtaining subsurface information useful in developing a conceptual model but have very limited usefulness in direct detection and quantification of DNAPL because of a lack of demonstrated methods, documented successes, and personnel trained in using these techniques for DNAPLs.

8t. There are no effective, non-intrusive methods to locate DNAPL pools or residuum in a static system.

9. Noninvasive geophysical techniques could possibly detect very large pools of DNAPL and be able to track the progress of a remediation process.

10. Any device or method developed to merely detect DNAPL should be extremely simple and even then the development may not give a reasonable return on investment. 
$11^{*}$. CI VOCs migrate in the subsurface as vapor in soil gas, solutes in groundwater, and as DNAPL; the DNAPL migration is governed by saturation, interfacial tension, wettability, capillary pressure, residual saturation, permeability, solubility, vapor pressure, density, and viscosity.

12*. Conceptual models describe the behavior of DNAPL in the subsurface and are used to guide site characterization and remedial activities.

$13^{*}$. Without adequate precautions and understanding of DNAPL behavior, site characterization activities may enhance contamination by DNAPL and increase remedial cost.

14t. Intrusive methods of DNAPL detection have a low probability of encountering freephase and can result in a worsening of the problem by causing remobilization of stable pools.

15. Documentation of observations made during drilling, such as the occurrence of distinctive chemical odors, can be very useful for DNAPL site characterization.

$16^{*}$. Subsurface characteristics should be delineated, particularly the presence of fine grained capillary barriers and preferential DNAPL migration pathways.

17t. Subsurface heterogeneities at a site make it difficult to predict with any degree of certainty the migration pathways of DNAPLs and regions of accumulation of DNAPL pools and residuals.

$18^{*}$. DNAPL presence can be: (1) determined directly by various visual examinations of subsurface samples; (2) inferred by chemical analysis of subsurface samples; and/or (3) suspected based on interpretation of anomalous chemical distributions in water and soil gas.

19*. Information obtained from noninvasive methods such as surface geophysical surveys, soil gas analysis, and current and archived aerial photographs are used to refine the conceptual model of a site and to guide subsequent invasive field work.

$20^{*}$. Soil gas surveys are effective in guiding invasive field work because they yield data concerning contaminant source areas, contaminated shallow groundwater, and contaminated soil gas.

$21^{*}$. Invasive activities are required to gather information necessary to refine the conceptual model for use in estimating the nature and extent of the contamination and in making decisions regarding possible remedies.

22. Monitoring activities during remediation should be regarded as a continuation of characterization activities.

23. When DNAPLs are present or suspected, intelligent interpretation of all the site and laboratory data is essential during all phases of characterization and remediation. 


\section{APPENDIX B}

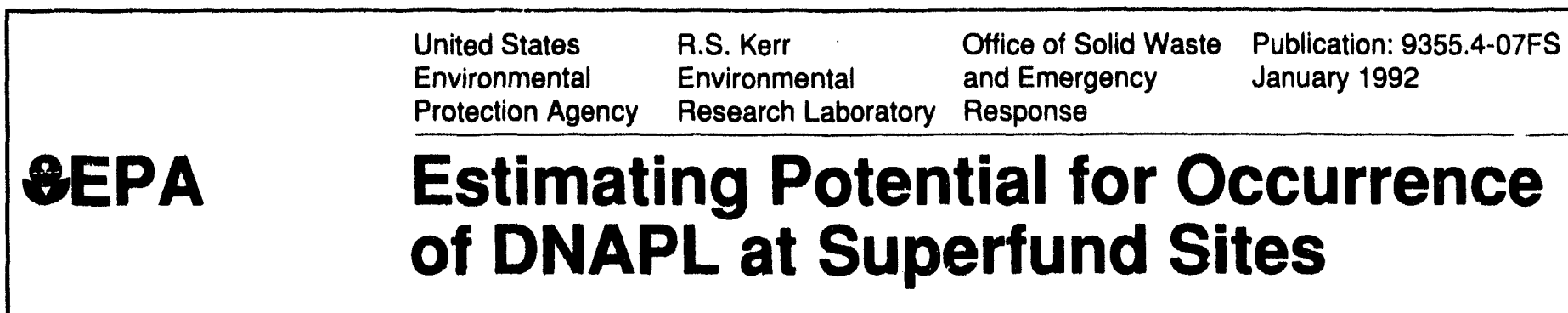

Office of Emergency and Remedial Response

Hazardous Site Control Division (OS-220W)

Quick Reference Fact Sheet

\section{GOALS}

The presence of Dense Nonaqueous Phase Liquids (DNAPL) in soils and aquifers can control the ultimate success or failure of remediation at a hazardous waste site. Because of the complex nature of DNAPL transport and fate, however, DNAPL may often be undetected by direct methods, leading to incomplete site assessments and inadequate remedial designs. Sites affected by DNAPL may require a different "paradigm," or conceptual framework, to develop effective characterization and remedial actions (2).

To help site personnel determine if DNAPL-based characterization strategies should be employed at a particular site, a guide for estimating the potential for DNAPL occurrence was developed. The approach,- described in this fact sheet, requires application of two types of existing site information:

\section{- Historical Site Use Information}

\section{- Site Characterization Data}

By using available data, site decision makers can enter a system of two flowcharts and a classification matrix for estimating the potential for DNAPL occurrence at a site. If the potential for DNAPL occurrence is low, then conventional site assessment and remedial actions may be sufficient. If the potential for DNAPL is moderate or high, however, a different conceptual approach may be required to account for problems associated with DNAPL in the subsurface.

\section{BACKGROUND}

DNAPLs are separate-phase hydrocarbon liquids that are denser than water, such as chlorinated solvents (either as a single component or as mixtures of solvents), wood preservative wastes, coal tar wastes, and pesticides. Until recently, standard operating practice in a variety of industries resulted in the release of large quantities of DNAPL to the subsurface. Most DNAPLs undergo only limited degradation in the subsurface, and persist for long periods while slowly releasing soluble organic constituents to ground water through dissolution. Even with a moderate DNAPL release, dissolution may continue for hundreds of years or longer under natural conditions before all the DNAPL is dissipated and concentrations of soluble organics in ground water return to background levels.

DNAPL exists in the soil/aquifer matrix as free-phase DNAPL and residual DNAPL. When released at the surface, freephase DNAPL moves downward through the soil matrix under the force of gravity or laterally along the surface of sloping fine-grained stratigraphic units. As the free-phase DNAPL moves, blobs or ganglia are trapped in pores and/or fractures by capillary forces (7). The amount of the trapped DNAPL, known as residual saturation, is a function of the physical properties of the DNAPL and the hydrogeologic characteristics of the soil/aquifer medium and typically ranges from $5 \%$ to $50 \%$ of total pore volume. At many sites, however, DNAPL migrates preferentially through small-scale fractures and heterogeneities in the soil, permitting the DNAPL to penetrate much deeper than would be predicted from application of typical residual saturation values (16).

Once in the subsurface, it is difficult or impossible to recover all of the trapped residual DNAPL. The conventional aquifer remediation approach, ground water pump-and-treat, usually removes only a small fraction of trapped residual DNAPL $(11,21,26)$. Although many DNAPL removal technologies are currently being tested, to date there have been no field demonstrations where sufficient DNAPL has been successfully recovered from the subsurface to return the aquifer to drinking water quality. The DNAPL that remains trapped in the soil/aquifer matrix acts as a continuing source of dissolved contaminants to ground water, preventing the restoration of DNAPL-affected aquifers for many years. 


\section{DNAPL TRANSPORT AND FATE - CONCEPTUAL APPROACHES}

The major factors controlling DNAPL migration in the subsurface include the following (5):

- the volume of DNAPL released;

- the area of infiltration at the DNAPL entry point to the subsurface;

- the duration of release;

- properties of the DNAPL, such as density, viscosity, and interfacial tension;

- properties of the soil/aquifer media, such as pore size and permeability;

- general stratigraphy, such as the location and topography of low-permeability units;

- micro-stratigraphic features, such as root holes, small fractures, and slickensides found in silt/clay layers.

To describe the general transport and iate properties of DNAPL in the subsurface, a series of conceptual mocicls (24) are presented in the following figures:

\section{Case 1: DNAPL Release to Vadose Zone Only}

After release on the surface, DNAPL moves vertically downward under the force of gravity and soil capillarity. Because only a small amount of DNAPL was released, all of the mobile DNAPL is eventually trapped in pores and fractures in the unsaturated zone. Infiltration through the DNAPL zone dissolves some of the soluble organic constituents in the DNAPL, carrying organics to the water table and forming a dissolved organic plume in the aquifer. Migration of gaseous vapors can also act as a source of dissolved organics to ground water (13).

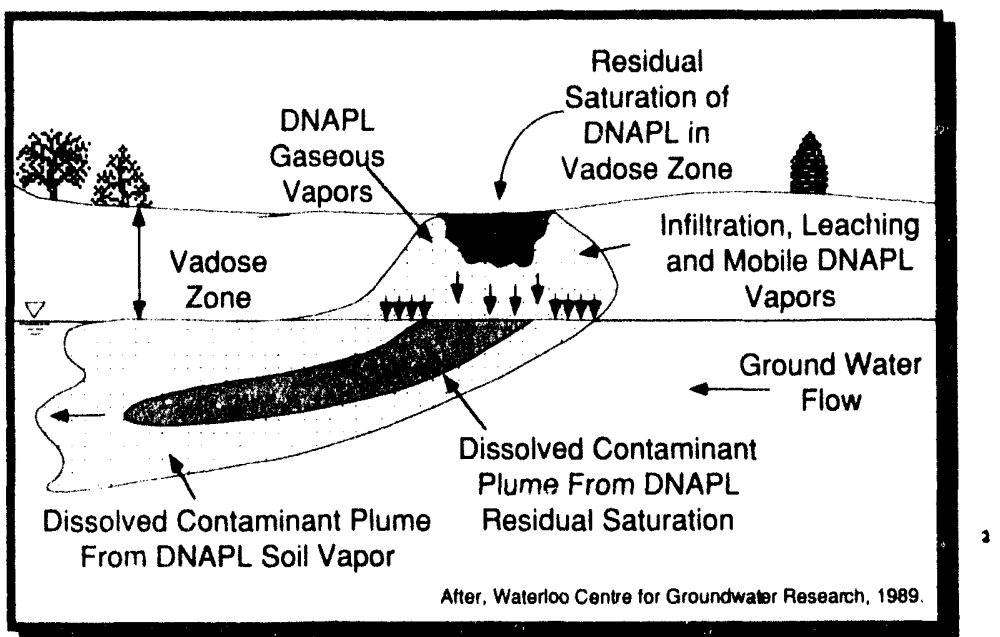

\section{Case 2: DNAPL Relcase to Unsaturated and Saturated Zones}

If enough DNAPL is released at the surface, it can migrate all the way through the unsaturated zone and reach a water-bearing unit. Because the specific gravity of DNAPL is greater than water, it continues downward until the mobile DNAPL is exhausted and is trapped as a residual hydrocarbon in the porous media. Ground water flowing past the trapped residual DNAPL dissolves soluble components of the DNAPL, forming a dissolved plume downgradient of the DNAPL zone. As with Case 1, water infiltrating down from the source zone also carries dissolved constituents to the aquifer and contributes further to the dissolvert plume.

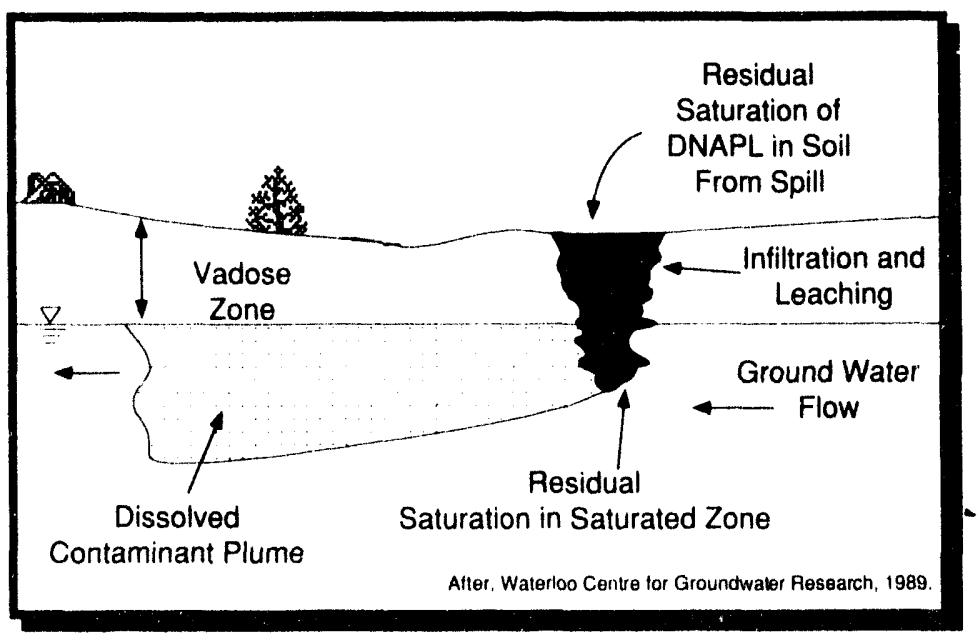




\section{Case 3: DNAPL. Pools and Effect of Low- Permeability Units}

Mobile DNAPL will continue vertical migration until it is trapped as a residual hydrocarbon (Case 1 and Case 2) or until low-permeability stratigraphic units are encountered which create DNAPL "pools" in the soil/aquifer matrix. In this figure, a perched DNAPL pool fills up and then spills over the lip of the low-permeability stratigraphic unit. The spill-over point (or points) can be some distance away from the original source, greatly complicating the process of tracking the DNAPL migration.

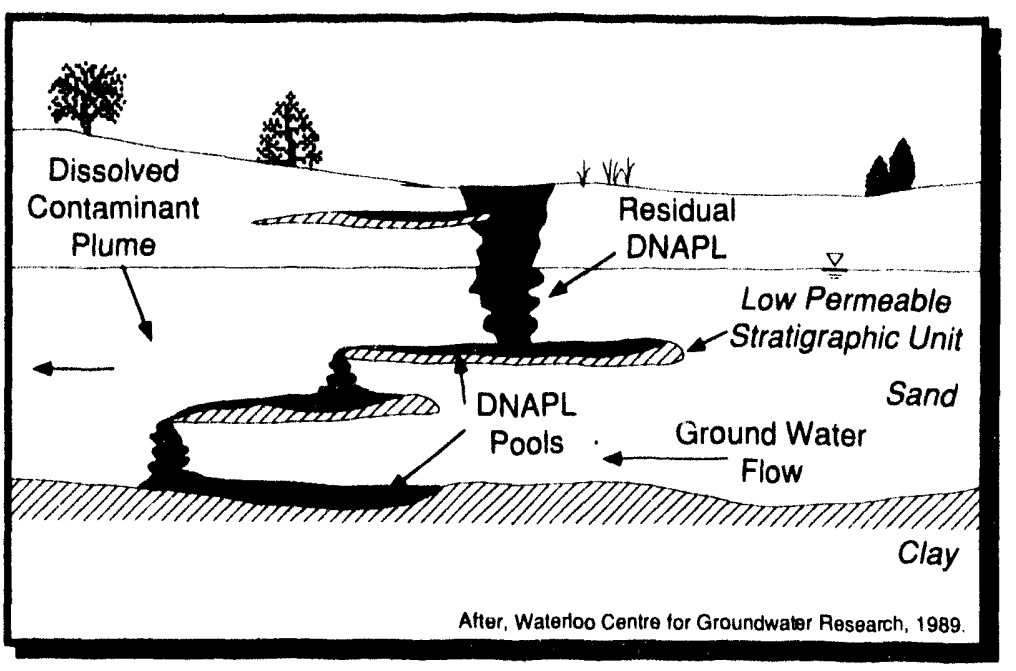

\section{Case 4: Composite Site}

In this case, mobile DNAPL migrates vertically downward through the unsaturated zone and the first saturated zone, producing a dissolved constituent plume in the upper aquifer. Although a DNAPL pool is formed on the fractured clay unit, the fractures are large enough to permit vertical migration downward to the deeper aquifer (see Case 5, below). DNAPL pools in a topographic low in the underlying impermeable unit and a second dissolved constituent plume is formed.

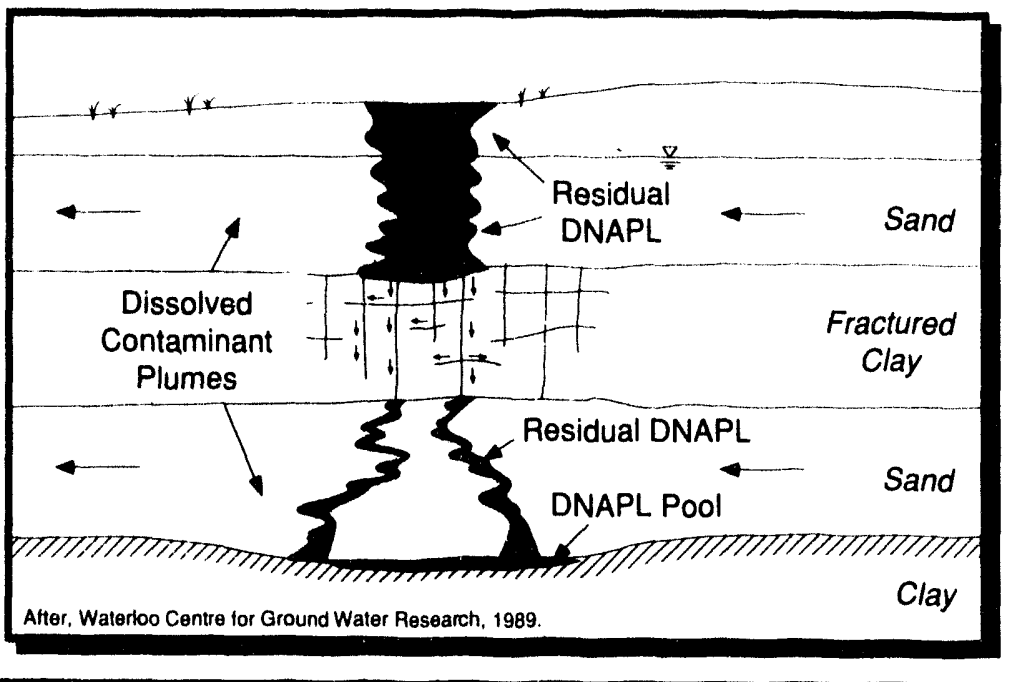

\section{Case 5: Fractured Rock or Fractured Clay System}

DNAPL introduced into a fractured rock or fractured clay system follows a complex pathway based on the distribution of fractures in the original matrix. The number, density, size, and direction of the fractures usually cannot be determined due to the extreme heterogeneity of a fractured system and the lack of economical aquifer characterization technologies. Relatively small volumes of DNAPL can penetrate deeply into fractured systems due to the low retention capacity of the fractures and the ability of some DNAPLs to migrate through very small $\quad<20$ microns) fractures. Many clay units, once considered to be relatively impermeable to DNAPL migration, often act as fractured media with preferential pathways for vertical and horizontal DNAPL migration.

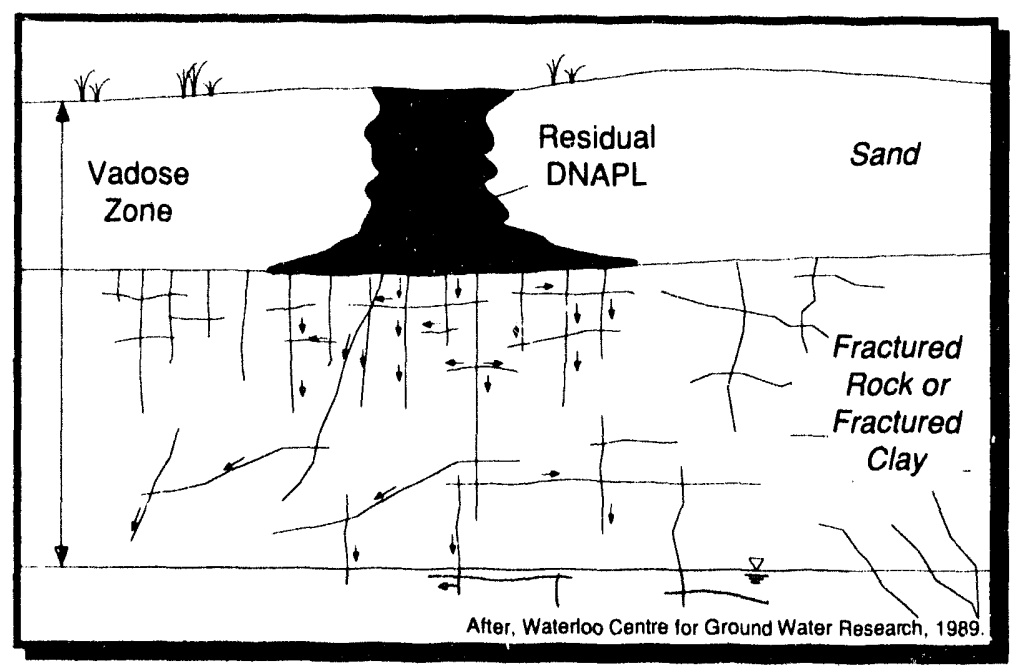




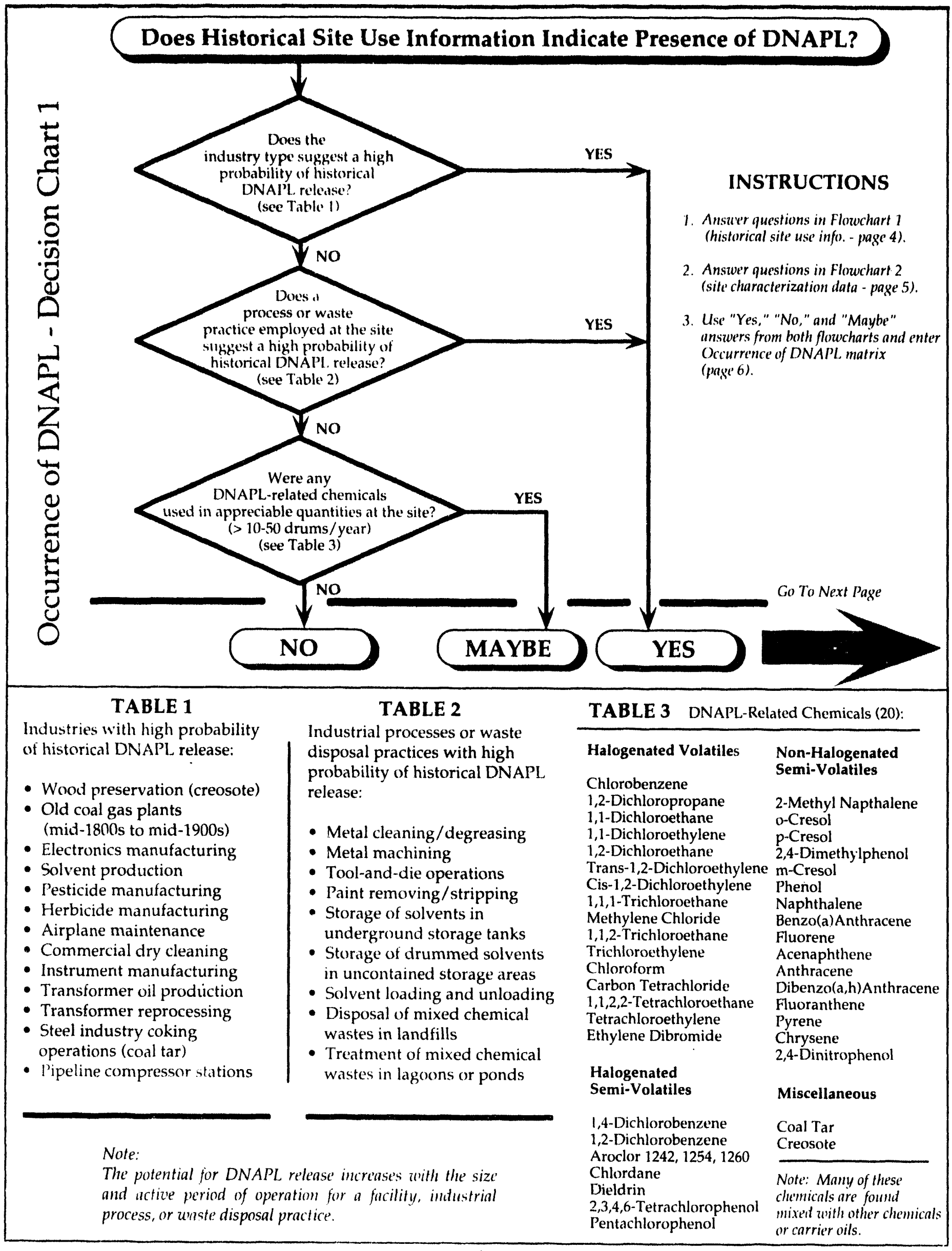




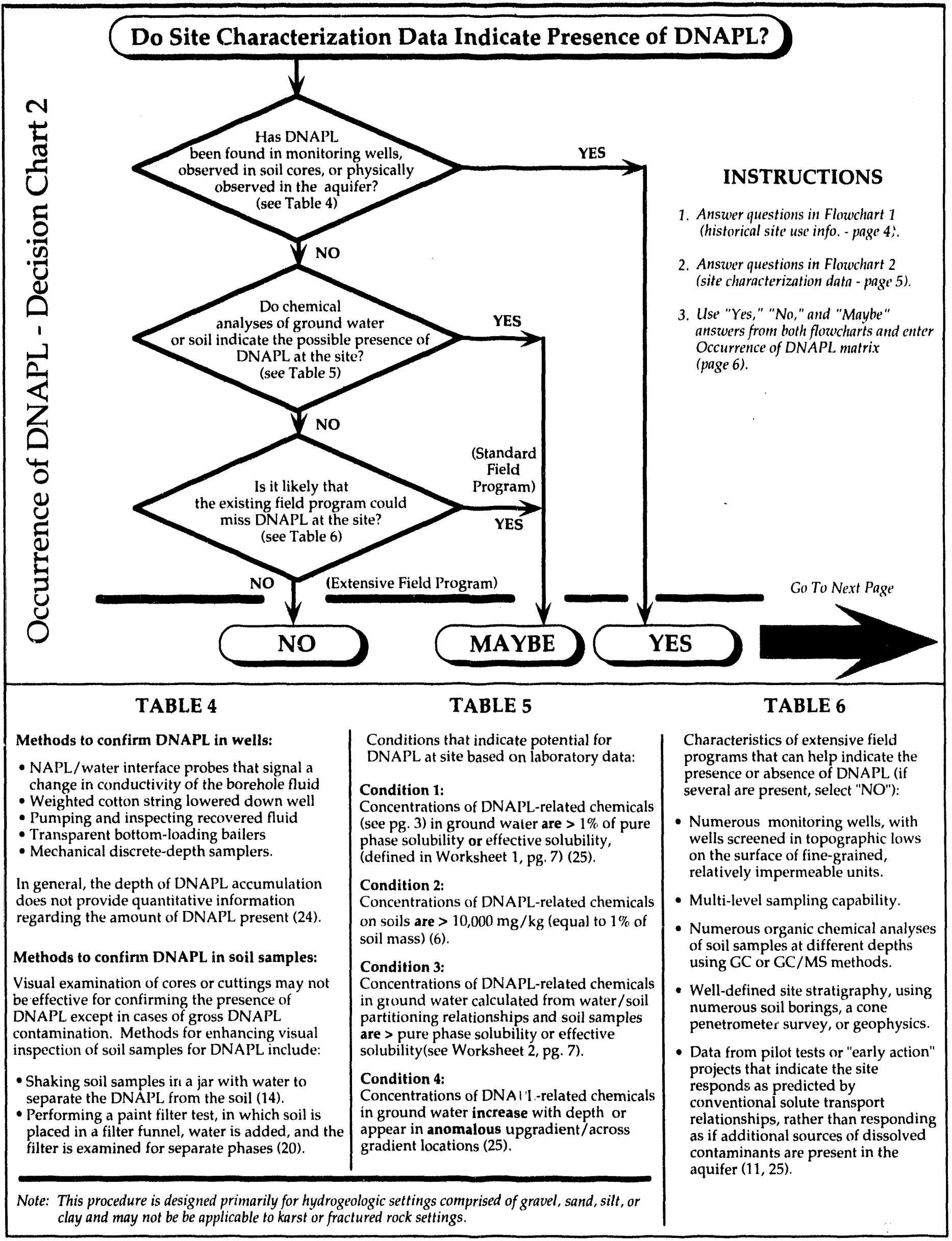




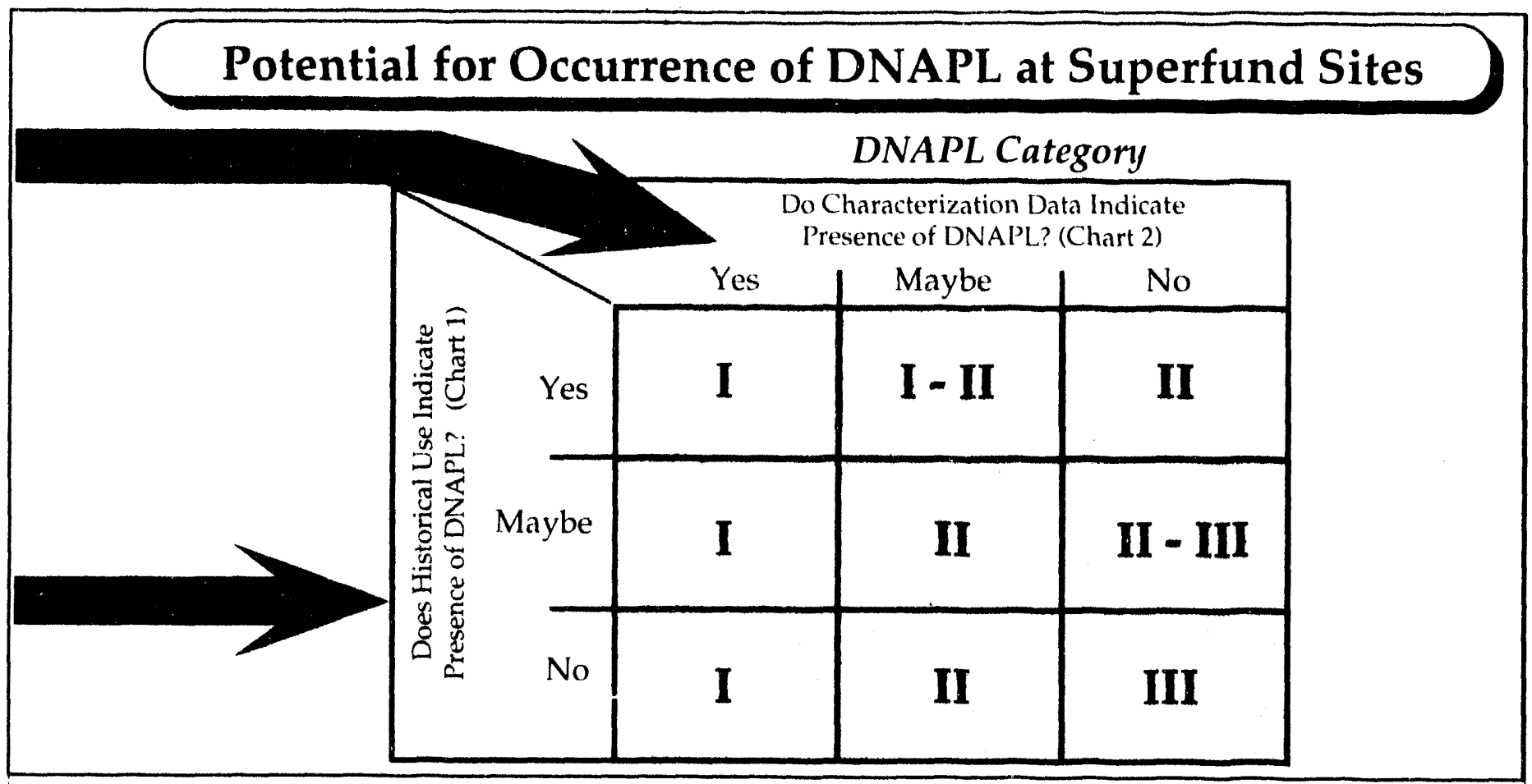

Category

1 Confirmed or high potential for DNAPL at site.

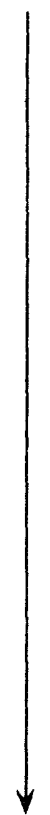

- The risk of spreading contaminants increases with the proximity to a potential DNAPL zone. Special precautions should be taken to ensure that drilling does not create pathways for continued vertical migration of free-phase DNAPLs. In DNAPL zones, drilling should be suspended when a lowpermeability unit or DNAPL is first encountered. Wells should be installed with short screens $(\leq 10$ feet). If required, deeper drilling through known DNAPL zones should be conducted only by using double or triple-cased wells to prevent downward migration of DNAPL. As some DNAPLs can penetrate fractures as narrow as 10 microns, special care must be taken during all grouting, cementing, and well sealing activities conducted in DNAPL zones.

- In some hydrogeologic settings, such as fractured crystalline rock, it is impossible to drill through DNAPL with existing technology without causing vertical migration of the DNAPL down the borehole, even when double or triple casing is employed (2).

- The subsurface DNAPL distribution is difficult to delineate accurately at some sites. DNAPL migrates preferentially through selected pathways (fractures, sand layers, etc.) and is affected by small-scale changes in the stratigraphy of an aquifer. Therefore, the ultimate path taken by DNAPL can be very difficult to characterize and predict.

- In most cases, fine-grained aquitards (such as clay or silt units) should be assumed to permit downward migration of DNAPL through fractures unless proven otherwise in the field. At some sites it can be exceptionally difficult to prove otherwise even with intensive site investigations (2).

- Drilling in areas known to be DNAPL-free should be performed before drilling in DNAPL zones in order to form a reliable conceptual model of site hydrogeology, stratigraphy, and potential DNAPL pathways. In areas where it is difficult to form a reliable conceptual model, an "outside-in" strategy may be appropriate: drilling in DNAPL zones is avoided or minimized in favor of delineating the outside dissolved-phase plume (2). Many fractured rock settings may require this approach to avoid opening further pathways for DNAPL migration during site assessment.

II Moderate potential for

- Due to the potential risk for exacerbating ground-water contamination problems during drilling DNAPL at site.

III Low potential for DNAPL at site. through DNAIL zones, the precautions described for Category I should be considered during site assessment. Further work should focus on determining if the site is a "DNAPL site."
- DNAPL is not likely to be a problem during site characterization, and special DNAPL precautions are probably not needed. Floating free-phase organics (INAILs), smption, and other factors can complicate site assessment and remediation activities, however. 


\section{Worksheet 1: Calculation of Effective Solubility (from Shiu, 1988; Feenstra, Mackay, \& Cherry, 1991)}

For a single-component DNAPL, the pure-phase solubility of the organic constituent can be used to estimate the theoretical upper-level concentration of organics in aquifers or for performing dissolution calculations. For DNAPLs comprised of a mixture of chemicals, however, the effective solubility concept should be employed:

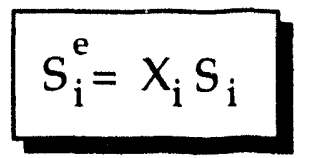

$\mathrm{S}_{\mathrm{i}}^{\mathrm{e}}=$ the effective solubility (the theoretical upper-level dissolved-phase concentration

Where of a constituent in ground water in equilibrium with a mixed DNAPL; in $\mathrm{mg} / 1$ )

$X_{i}=$ the mole fraction of component $i$ in the DNAPL mixture (obtained from a lab analysis of a DNAPL sample or estimated from waste characterization data)

$\mathrm{S}_{\mathrm{i}}=$ the pure-phase solubility of compound $\mathrm{i}$ in $\mathrm{mg} / 1$ (usually obtained from literature sources)

For example, if a laboratory analysis indicates that the mole fraction of trichloroethylene (TCE) in DNAPL is 0.10 , then the effective solubility would be $110 \mathrm{mg} / 1$ [pure phase solubility of TCE times mole fraction TCE: $(1100 \mathrm{mg} / \mathrm{l}) *(0.10)=110$ $\mathrm{mg} / \mathrm{l}$. Effective solubilities can be calculated for all components in a DNAPL mixture. Insoluble organics in the mixture (such as long.chained alkanes) will reduce the mole fraction and effective solubility of more soluble organics but will not contribute dissolved-phase organics to ground water. Please note that this relationship is approximate and does not account for non-ideal behavior of mixtures, such as co-solvency, etc.

\section{Worksheet 2: Method for Assessing Residual NAPL Based on Organic Chemical} Concentrations in Soil Samples (From Feenstra, Mackay, and Cherry, 1991)

To estimate if NAPLs are present, a partitioning calculation based on chemical and physical analyses of soil samples from the saturated zone (from cores, excavations, etc.) can be applied. This method tests the assumption that all of the urganics in the subsurface are either dissolved in ground water or adsorbed to soil (assuming dissolved-phase sorption, not the presence of NAPL). By using the concentration of organics on the soil and the partitioning calculation, a theoretical porewater concentration of organics in ground water is determined. If the theoretical pore-water concentration is greater than the estimated solubility of the organic constituent of interest, then NAPL may be present at the site. A worksheet for performing this calculation is presented below; see Feenstra, Mackay, and Cherry (1991) for the complete methodology.

Step 1: Calculate $\mathbf{S}_{\mathbf{i}}^{\mathbf{e}}$, the effective solubility of organic constituent of interest.

See Worksheet 1, above.

Step 2: Determine Koc, the organic carbon-water partition coefficient from one of the following:

A) Literature sources (such as 22) or

B) From empirical relationships based on Kow, the octanol-water partition coefficient, which is also found in the literature (22). For example, Koc can be estimated from Kow using the following expression developed for polyaromatic hydrocarbons (8):

$$
\log \mathrm{Koc}=1.0 * \log \mathrm{Kow}-0.21
$$

Other empirical relationships between $\mathrm{KoC}$ and Kow are presented in refs. 4 and 15.

Step 3: Determine foc, the fraction of organic carbon on the soil, from a laboratory analysis of clean soils from the site. Values for foc typically range from 0.03 to $0.00017 \mathrm{mg} / \mathrm{mg}$ (4). Convert values reported in percent to $\mathrm{mg} / \mathrm{mg}$.

Step 4: Determine or estimate $\rho b$, the dry bulk density of the soil, from a soils analysis. Typical values range from 1.8 to 2.1 $\mathrm{g} / \mathrm{ml}(\mathrm{kg} / \mathrm{l})$. Determine or estimate $\varphi \mathrm{w}$, the water-filled porosity.

Step 5: Determine $\mathrm{Kd}$, the partition (or distribution) coefficient between the pore water (ground water) and the soil solids:

$$
\mathrm{Kd}=\mathrm{Koc} * \mathrm{foc}
$$

Step 6: Using $\mathrm{Ct}$, the measured conc. of the organic compound in saturated soil in $\mathrm{mg} / \mathrm{kg}$, calculate the theoretical pore water conc. assuming no DNAPL (i.e., $\mathrm{Cw}$ in $\mathrm{mg} / \mathrm{l}$ ):

$$
C w=\frac{\left(C t^{*} \rho b\right)}{\left(K d^{*} \rho b+(\rho w)\right.}
$$

Step 7: Compare Cw and $S_{i}^{\mathbf{e}}$ (from Step 1):

$\mathrm{CW}>\mathrm{S}_{\mathrm{i}}^{\mathrm{e}}$ suggests possible presence of DNAPL

$\mathrm{Cw}<\mathrm{S}_{\mathrm{i}}^{\mathrm{e}}$ suggests possible absence of DNAPL 


\section{GLOSSARY (adapted from Cherry, 1991):}

DNAPL: A Dense Nonaqueous Phase Liquid. A DNAPL can be either a single-component DNAPL (comprised of only one chemical) or a mixed DNAPL (comprised of several chemicals). DNAPL exists in the subsurface as free-phase DNAPL or as residual DNAPL (see following definitions). DNAPL does not refer to chemicals that are dissolved in groundwater.

DNAPL ENTRY LOCATION: The area where DNAPL has entered the subsurface, such as a spill location or waste pond.

DNAPL SITE: A site where DNAPL has been released and is now present in the subsurface as an immiscible phase.

DNAPL ZONE: The portion of a site affected by free-phase or residual DNAPL in the subsurface (either the unsaturated zone or saturated zone). The DNAPL zone has organics in the vapor phase (unsaturated zone), dissolved phase (both unsaturated and saturated zone), and DNAPL phase (both unsaturated and saturated zone).

DISSOLUTION: The process by which soluble organic components from DNAPL dissolve in ground water or dissolve in infiltration water and form a ground-water contaminant plume. The duration of remediation measures (either clean-up or long-term containment) is determined by 1) the rate of dissolution that can be achieved in the field, and 2) the mass of soluble components in the residual DNAPL trapped in the aquifer.

EFFECTIVE SOLUBILITY: The theoretical aqueous solubility of an organic constituent in ground water that is in chemical equilibrium with a mixed DNAPL (a DNAPL containing several organic chemicals). The effective solubility of a particular organic chemical can be estimated by multiplying its mole fraction in the DNAPL mixture by its pure phase solubility (see Worksheet 1, page 7).

FREE-PHASE DNAPL: Immiscible liquid existing in the subsurface with a positive pressure such that it can flow into a well. If not trapped in a pool, free-phase DNAPL will flow vertically through an aquifer or laterally down sloping finegrained stratigraphic units. Also called mobile DNAPL or continuous-phase DNAPL.

PLUME: The zone of contamination containing organics in the dissolved phase. The plume usually will originate from the DNAPL zone and extend downgradient for some distance depending on site hydrogeologic and chemical conditions. To avoid confusion, the term "DNAPL plume" should not be used to describe a DNAPL pool; "plume" should be used only to refer to dissolved-phase organics.

POOL and LENS: A pool is a zone of free-phase DNAPL at the bottom of an aquifer. A lens is a pool that rests on a finegrained stratigraphic unit of limited areal extent. DNAPL can be recovered from a pool or lens if a well is placed in the right location.

RESIDUAL DNAPL: DNAPL held in soil pore spaces or fractures by capillary forces (negative pressure on DNAPL). Residual will remain trapped within the pores of the porous media unless the viscous forces (caused by the dynamic force of water against the DNAPL) are greater than the capillary forces holding the DNAPL in the pore. At most sites the hydraulic gradient required to mobilize all of the residual trapped in an aquifer is usually many times greater than the gradient that can be produced by wells or trenches (26).

RESIDUAL SATURATION: The saturation (the fraction of total pore space containing DNAPL) at which DNAPL becomes discontinuous and is immobilized by capillary forces (14). In unsaturated soils, residual saturation typically ranges from $5 \%$ to $20 \%$ of total pore volume, while in the saturated zone the residual saturation is higher, with typical values ranging from $15 \%$ to $50 \%$ of total pore volume $(14,17)$. At many sites, however, DNAPL migrates preferentially through small-scale fractures and heterogeneities in the soil, permitting the DNAPL to penetrate much deeper than would be predicted from application of typical residual saturation values (16).

\section{Defined Areas at a DNAPL Site}

DNAPL ZONE

(contains free-phase DNAPL in pools or lenses and/or residual DNAPL)

DNAPL ENTRY LOCATION

(such as a former waste pond)

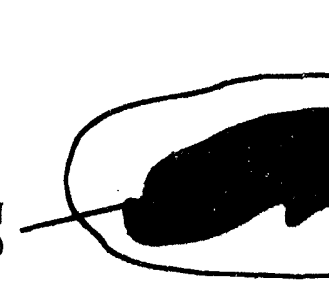

Dissolved-Phase PLUME

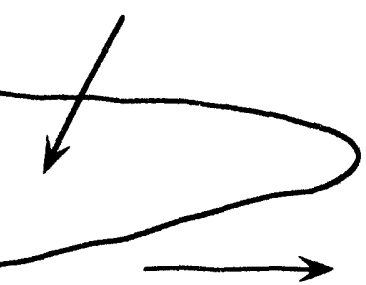

Ground Water Flow Direction 


\section{References}

1. Anderson, M.R., R.L. Johnson, and J.F. Pankow, The Dissolution of Residual Dense Non-Aqueous Phase Liquid (DNAPL) from a Saturated Porous Medium, Proc.: Petrol. Hcarb. and Org. Chemicals in Ground Water, NWWA, Houston, TX, Nov., 1987.

2. Cherry, J. A., written communication to EPP. DNAPL Workshop, Dallas, TX, R. S. Kerr Environmental Research Laboratory, U.S EPA, Ada, OK., Apr. 1991.

3. Connor, J.A., C.J. Newell, and D.K. Wilson, Assessment, Field Testing, and Conceptual Design for Managing Dense Nonaqueous Phase Liquids (DNAPL) at a Superfund Site, Proc.: Petrol. Hcarb. Org. Chemicals in Ground Water, NWWA, Houston, TX, 1989.

4. Domenico, P.A. and F. W. Schwartz, Physical and Chemical Hydrogeology Wiley, New York, NY, 1990.

5. Feenstra, S. and J.A. Cherry, Subsurface Contamination by Dense Non-Aqueous Phase Liquids (DNAPL) Chemicals, International Groundwater Symposium, International Assoc. of Hydrogeologists, Halifax, N.S., May 1-4, 1988.

6. Feenstra, S., D. M. MacKay, and J.A. Cherry, A Method for Assessing Residual NAPL Based on Organic Chemical Concentrations in Soil Samples, Groundwater Monit ing Review, Vol. 11, No. 2, 1991.

7. Hunt, J.R., N. Sitar, and K.D. Udell, Nonaqueous Phase Liquid Transport and Cleanup, Water Res. Research, Vol. 24 No. 8, 1991.

8. Karickhoff, S.W., D.S. Brown, and T.A. Scott, Sorption of Hydrophobic Pollutants on Natural Sediments, Water Res. R., Vol. 3, 1979.

9. Keller, C.K., G. van der Kamp, and J.A. Cherry, Hydrogeology of Two Saskatchewan Tills, L. of Hydrology, pp. 97-121, 1988. 10. Kueper, B.H. and E. O. Frind, An Overview of Immiscible Fingering in Porous Media, I. of Cont. Hydrology, Vol. 2, 1988.

11. Mackay, D.M. and J.A. Cherry, Ground-Water Contamination: Pump and Treat Remediation, ES\&T Vol. 23, No. 6, 1989.

12. Mackay, D.M., P.V. Roberts, and J.A. Cherry, Transport of Organic Contaminants in Ground Water, ES\&T, Vol. 19, No. 5, 1985.

13. Mendoza, C.A. and T. A. McAlary, Modeling of Ground-Water Contamination Caused by Organic Solvent Vapors, Ground Water Vol. 28, No. 2, 1990.

14. Mercer, J.W. and R.M. Cohen, A Review of Immiscible Fluids in the Subsurface: Properties, Models, Characterization and Remediation, I. of Cont. Hydrology Vol. 6, 1990.

15. Olsen, R.L. and A. Davis, Predicting the Fate and Transport of Organic Compounds in Groundwater, HMC, May/June 1990.

16. Poulson, M. and B.H. Kueper, A Field Experiment to Study the Behavior of Perchloroethylene in Unsaturated Porous Medium. Submitted to ES\&T, 1991.

17. Schwille, F., Dense Chlorinated Solvel.rs in Porous and Fractured Media: Model Experiments (English Translation), Lewis Publishers, Ann Arbor, MI, 1988.

18. Shiu, W.Y., A. Maijanen, A.L.Y. Ng, and D. Mackay, Preparation of Aqueous Solutions of Sparingly Soluble Organic Substances: II. Multicomponent System - Hydrocarbon Mixtures and Petroleum Products, Environ. Toxicology \& Chemistry, Vol. 7, 1988.

19. Sitar, N., J.R. Hunt, and J.T. Geller, Practical Aspects of Multiphase Equilibria in Evaluating the Degree of Contamination, Proc. of the Int. Asso. of Hydrog. Conf. on Subsurface Cont. by Immiscible Fluids, April 18 - 20, Calgary, Alb., 1990.

20. U.S. EPA, Dense Nonaqueous Phase Liquids, EPA Ground Water Issue Paper, EPA /540/4-91-002, 1991.

21. U.S. EPA, Evaluation of Ground-Water Extraction Remedies, Volume 1 (Summary Report) EPA/540/2-89/054, 1989.

22. Verschueren, K., Handbook of Environmental Data on Organic Chemicals, Van Nostrand Reinhold, New York, NY, 1983.

23. Villaume, J.F., Investigations at Sites Contaminated with Dense Non-Aqueous Phase Liquids (NAPLs), Ground Water Monitoring Review, Vol. 5, No. 2, 1985 .

24. Waterloo Centre for Ground Water Research, University of Waterloo Short Course, Dense Immiscible Phase Liquid Contaminants in Porous and Fractured Media, Kitchener, Ont., Dct., 1991.

25. Waterloo Centre for Ground Water Research, University of ' Vaterloo Short Course, Identification of DNAPL Sites: An Eleven Point Approach, Kitchener, Ont., Oct., 1991.

26. Wilson, J.L. and S.H. Conrad, Is Physical Displacement of Residual Hydrocarbons a Realistic Possibility in Aquifer Restoration?, Proc.: Petrol. Hcarb. and Org. Chemicals in Ground Water, NWWA, Houston, TX, N'W'WA. Nov. 5-7, 1984

NOTICE: The policies and procedures set out in this document are intended solely as guidance. They are not intended, nor can they be relied upon, to create any rights enforcenble by any party in litigation with the United States. EPA officials may decide to follow the guidance provided in this memorandum, or to act at variance with the guidance, based on an analysis of specific site circumstances. The Agency also reserves the right to change this guidance at any time without public notice.

For more information, contact: Randall R. Ross

R. S. Kerr Environmental Research Laboratory

Office of Research and Development

U.S. Environmental Protection Agency

Ada, Oklahoma 74820

Authors: Charles \}. Newell, Groundwater Services, Inc., Houston, Texas

Randall R. Ross, R. S. Kerr Environmental Research Laboratory 
This page is intentionally blank. 


\section{APPENDIX C}

\section{Glossary}

The unmarked terms listed below are used in the text; those indicated with an asterisk are included because they are frequently used in other reports that address DNAPL problems.

*Advection - the transport of contaminating material by the bulk mass of flowing fluid.

"Capillary Fringe - the saturated zone overlying the water table where a liquid is under tension.

*CERCLA - an acronym for the Comprehensive Environmental Besponse Compensation and Liability Act of 1980 which established a national program in the U. S. to respond to past releases of hazardous substances into the environment.

Chlorinated VOCs - chlorinated volatile organic compounds such as carbon tetrachloride $\left(\mathrm{CCl}_{4}\right)$, trichloroethylene (TCE), trichloroethane (TCA), and tetrachloroethylene (PCE).

CI VOCs - chlorinated VOCs

CMST-IP - Characterization Monitoring and Sensor Iechnology- Integrated Program of the Office of Technology Development (OTD) of DOE.

Conceptual Model - a formulated hypothesis about the presence of DNAPL, its transport and fate based on available information about a site, and the understanding of processes that influence the distribution of a chemical in the subsurface.

"Confinement - action to restrict contamination within defined boundaries.

"Containment - ongoing activity to prevent spreading of contamination.

Data Fusion - the process whereby all the information about a site is considered intelligently in making decisions about characterization, risk, remediation, and monitoring.

*Desorption - the release of material from a solid to the liquid or gas phase.

Diffusion - contaminant spreading as a result of random motion of molecules.

Dispersion - spreading and mixing of contaminants in ground water caused by diffusion and turbulence.

Dissolution - the process by which components from DNAPL dissolve in groundwater. 
"Distribution Coefficient - the quantity of the solute sorbed by the solid per unit weight of solid divided by the quantity dissolved in the water per unit volume of water.

DNAPL - an acronym for a denser-than-water nonaqueous phase liquid that is synonymous with dense immiscible phase liquid and is used exclusively for the nonaqueous phase liquid present in the subsurface and not for the chemical present in solution.

DNAPL Entry Location - an area where a chemical or mixture that can form a DNAPL has entered the subsurface by way of a leak, spill, discharge, or any other escape.

DNAPL Lens - a zone of free-phase DNAPL, smaller than a pool, resting on low permeability strata.

DNAPL Pool - a zone of free-phase DNAPL resting on an impermeable or semipermeable layer in the subsurface.

DNAPL Site - a location where a chemical or mixture has been released and is now present in the subsurface as an immiscible phase liquid.

DNAPL Zone - the portion of either the vadose or saturated zone, or both zones, affected by the presence of free-phase or residual DNAPL that can cause contamination as a vapor in the vadose zone and as a water solute in both the vadose and saturated zone.

"Effective Solubility - the theoretical aqueous solubility of an organic constituent in groundwater that is in equilibrium with a DNAPL containing several organic chemicals.

"Emulsion - the dispersion of very small drops of one liquid in an immiscible liquid, such as DNAPL in water.

*Fingering - the movement of DNAPL in a porous medium that results in the formation of finger-shaped globs of DNAPL at the leading edge of the main movement.

"Gravity Drainage - the movement of DNAPL in an aquifer that results from the force of gravity.

Groundwater Remediation - a very general term referring to all activities taken to improve groundwater quality or control the spread of groundwater contamination, such as plume capture or control, DNAPL removal, or groundwater restoration.

"Groundwater Restoration - the removal of subsurface contamination to the degree necessary to achieve appropriate cleanup levels which protect public health and the environment.

"Groundwater DNAPL Zone - DNAPL below the water table in either the residual or free-phase state.

*Henry's Law Constant - the equilibrium ratio of the partial pressure of a compound in air to the concentration of the compound in water. 
Immiscible Liquids - liquids that coexist as separate phases because they do not have mutual solubility.

Immobile DNAPL - DNAPL that cannot migrate as a separate phase because it is held as residual or is constrained by a stratigraphic (capillary) trap or hydraulic forces.

LNAPL - an acronym for less-dense-than-water nonaqueous phase liquid that is synonymous with less-dense-than-water immiscible phase liquid.

OTD - Office of Technology Development.

"PAHs - an acronym for polycyclic aromatic hydrocarbons.

"PCBs - an acronym for polyçhlorinated biphenyls.

Permeability - a property of the subsurface that is dependent on the shape and size of the openings through which a liquid moves under a potential gradient.

Plume - a term almost exclusively used to refer to a zone of dissolved contamination but sometimes used to refer to vapor contamination in the vadose zone.

Porosity - The ratio of the volume of all the pores in a material to the volume of the whole.

"Raoult's Law - a law used to estimate the effective solubility of individual DNAPL components of a DNAPL mixture.

"RCRA - is an acronym for the Resource Conservation and Becovery Act which regulates monitoring, investigation, and corrective action activities at all hazardous treatment, storage, and disposal facilities.

Residual DNAPL - the immiscible liquid held in the pore space or fractures by capillary tension, such that it cannot move or be mobilized by reasonable hydraulic forces.

Residual Saturation - the fraction of total pore space containing DNAPL (0.05 to 0.20 in the vadose zone and 0.15 to 0.50 in the saturated zone).

*RVFS - an acronym for remedial jnvestigation / feasibility study.

Risk Assessment - an evaluation of the potential for exposure to contaminants and the associated hazard.

Soil Gas - gas (vapors) in the soil above the saturated zone.

Soil Gas Survey - collection and analysis of samples of soil gas for investigation of the presence of volatile organic compounds in soil and shallow groundwaters.

*Sorption - capture of material from a fluid phase by a solid phase.

Source - within the context of conceptual models of DNAPL, a source is a mass of DNAPL present below ground level as a residual, pool, lens, or finger. 
Threshold Entry Pressure - the capillary pressure that must be overcome for a DNAPL to enter a water-saturated medium.

Vadose DNAPL Zone - DNAPL present above the water table in either the residual or free-phase state and generally the cause of contaminated soil gas, residual water, and groundwater.

Vadose Zone - the unsaturated zone of the subsurface that extends between the ground surface and the water table.

Viscosity - internal friction within a liquid that causes it to resist flow.

VOC - an acronym for volatile organic compounds.

Volumetric Retention Capacity - the capacity of the vadose zone to trap DNAPL which is typically reported in liters of residual DNAPL per cubic meter of media.

C-4 

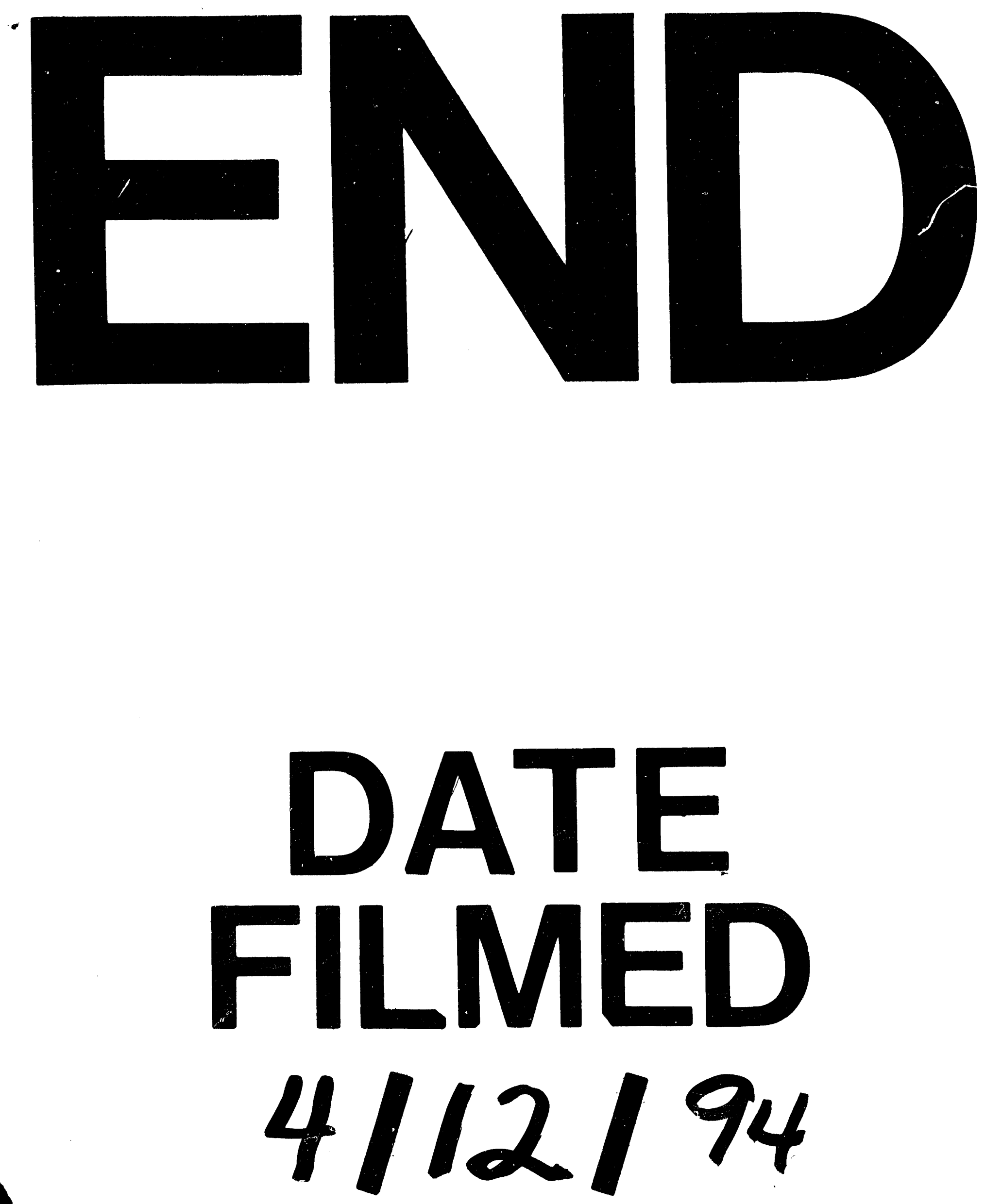

1 
